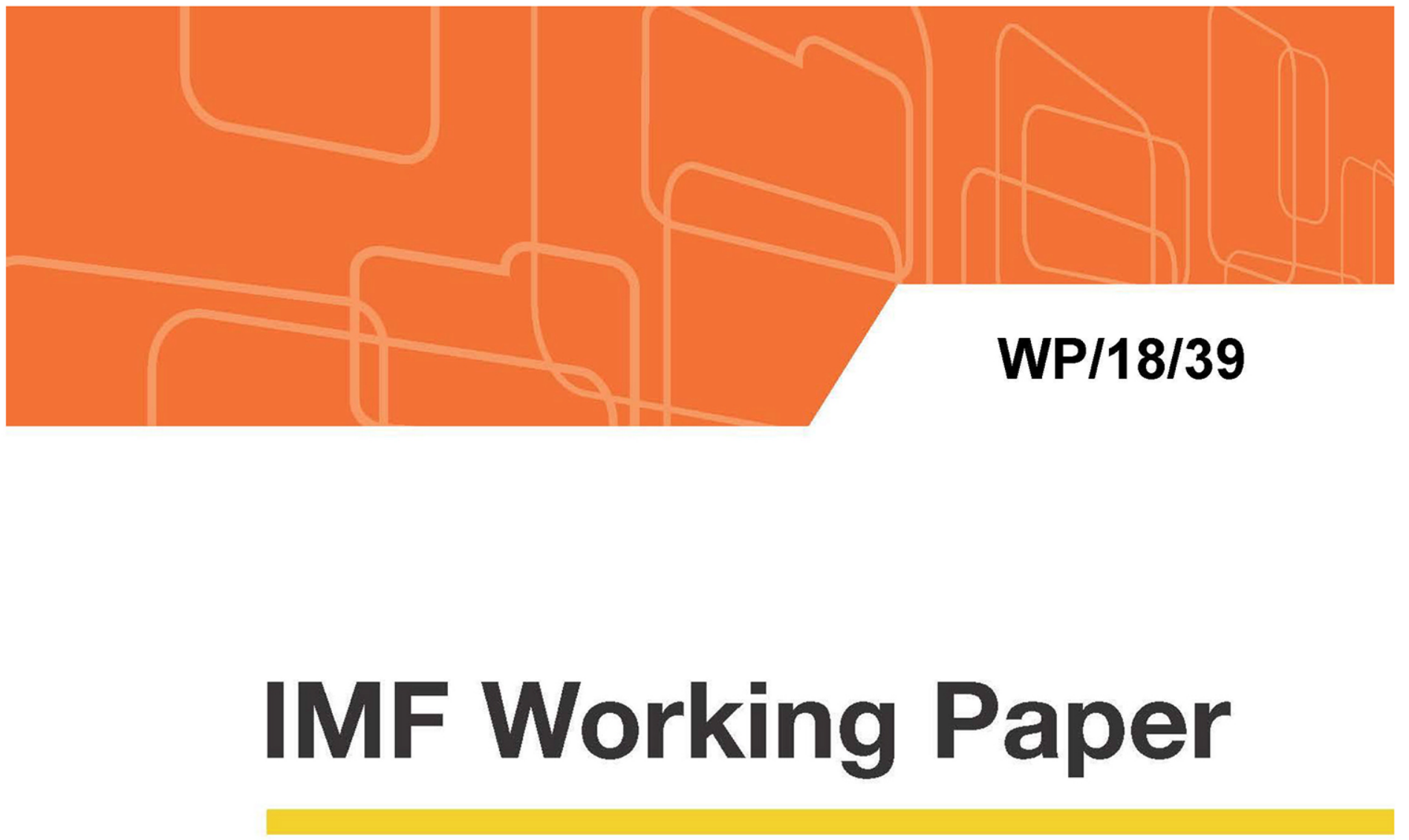

\title{
How Well Do Economists Forecast Recessions?
}

by Zidong An, João Tovar Jalles, and Prakash Loungani

IMF Working Papers describe research in progress by the author(s) and are published to elicit comments and to encourage debate. The views expressed in IMF Working Papers are those of the author(s) and do not necessarily represent the views of the IMF, its Executive Board, or IMF management. 


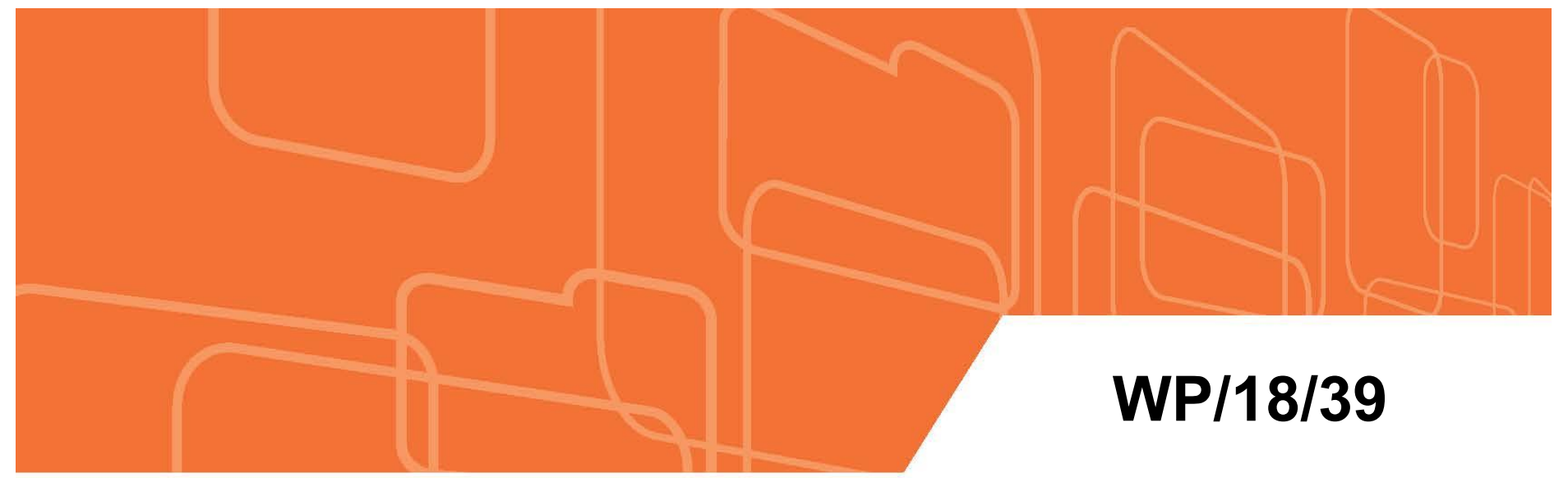

\section{IMF Working Paper}

\section{How Well Do Economists Forecast Recessions?}

by Zidong An, João Tovar Jalles, and Prakash Loungani 


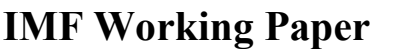

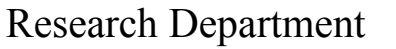

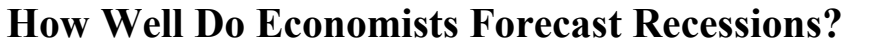

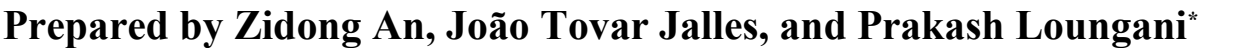

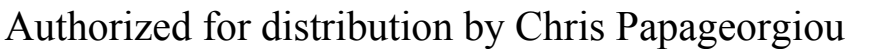

$\operatorname{March} \amalg \amalg \square$

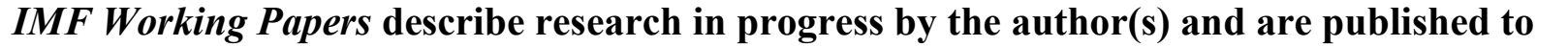

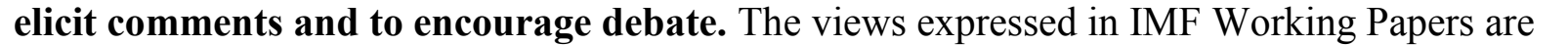

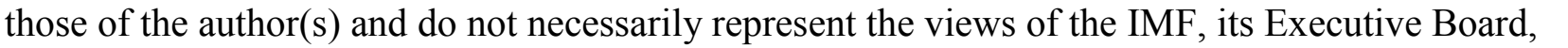

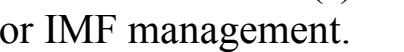

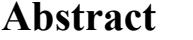

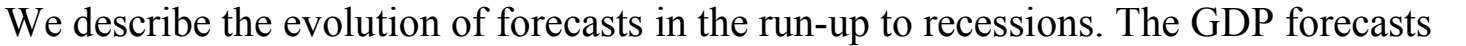

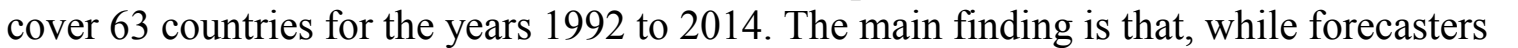

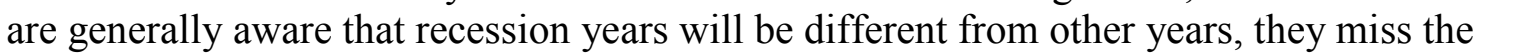

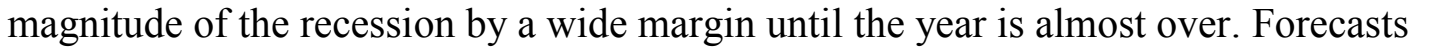

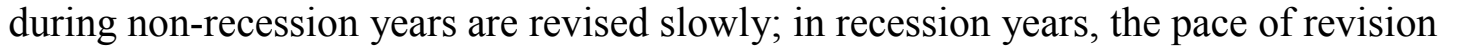

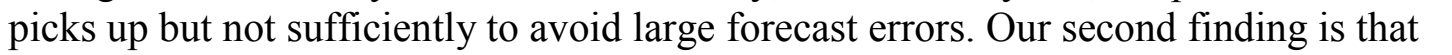

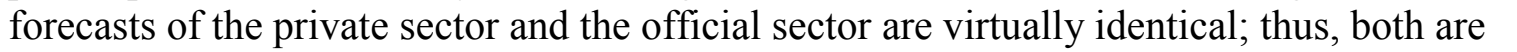

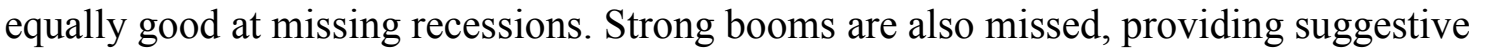

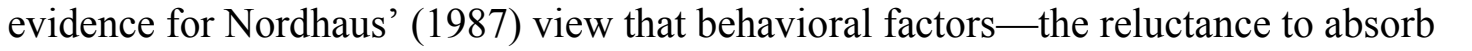

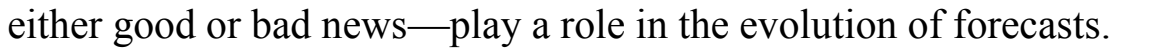

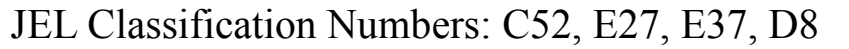

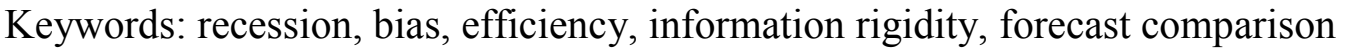

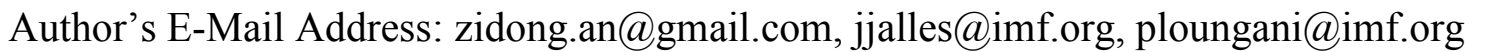

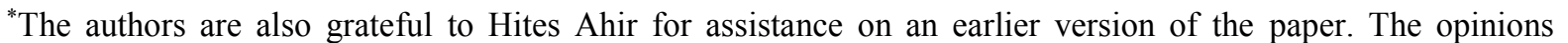

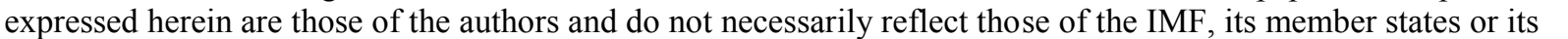

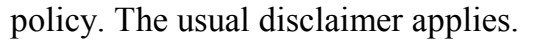


$\square$

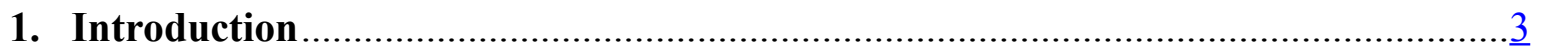

\begin{tabular}{c}
\hline \\
\hline
\end{tabular}

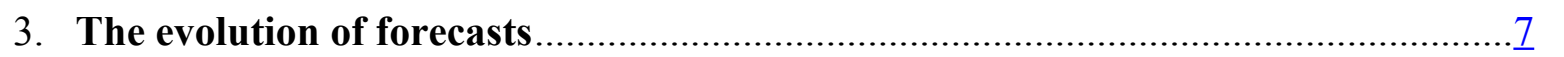

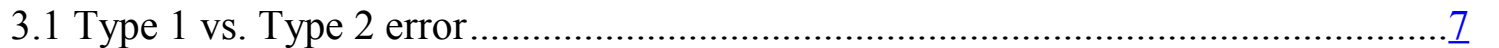

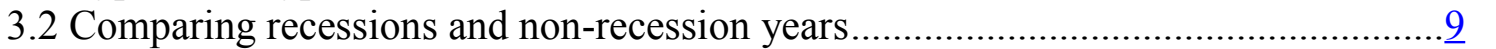

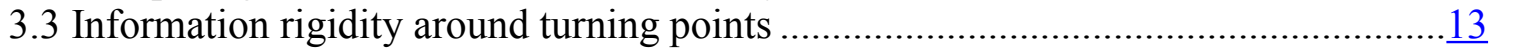

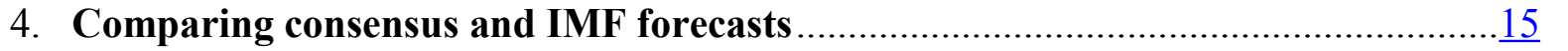

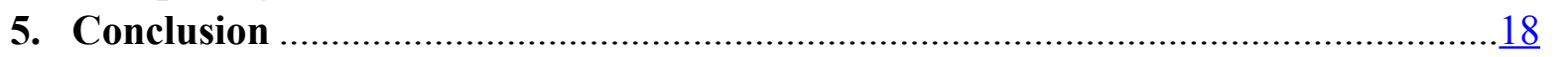

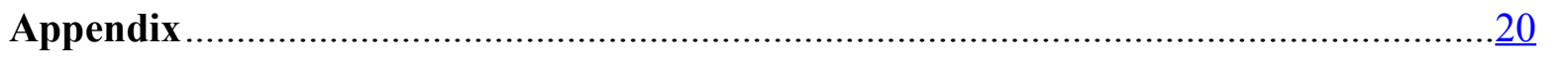
$\square$

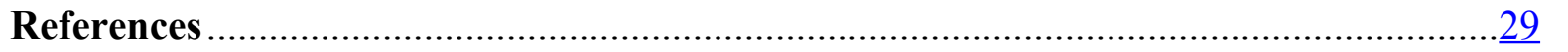
$\square$

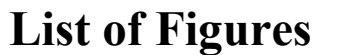

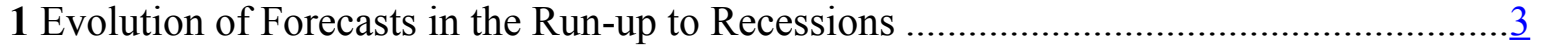

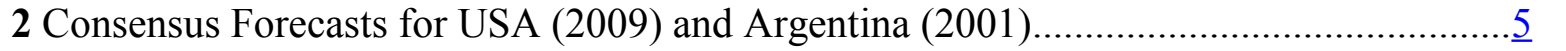

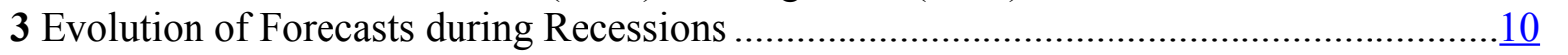

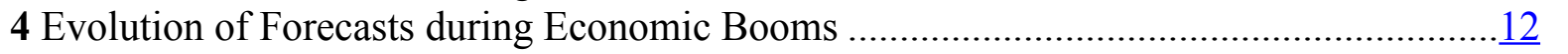

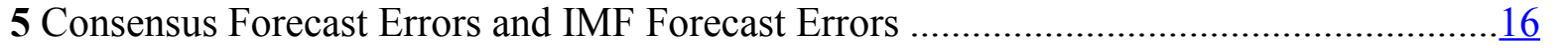

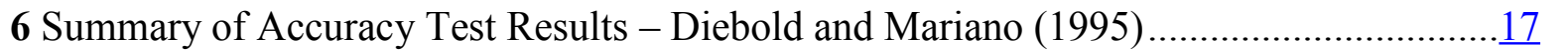

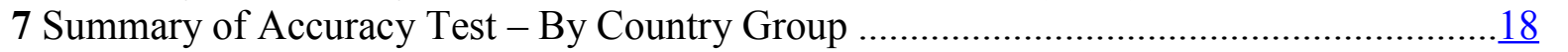

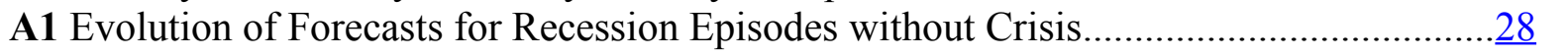
$\square$

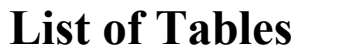

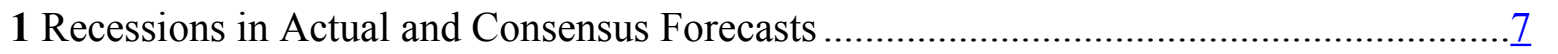

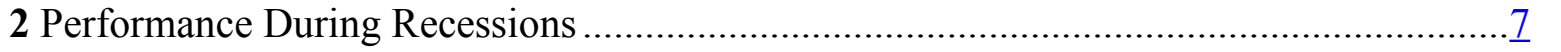

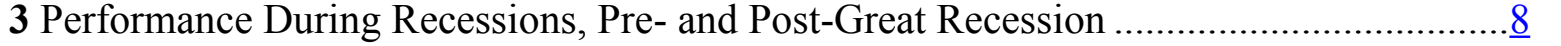
ए

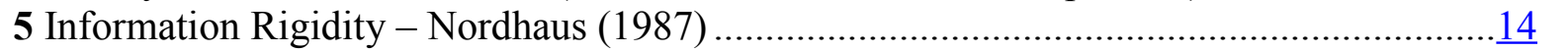
प

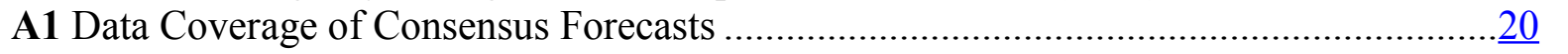

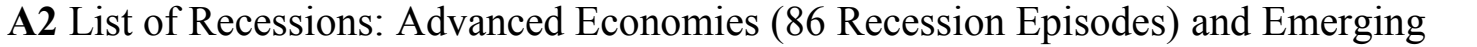

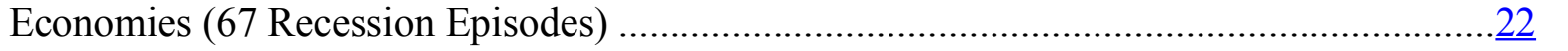

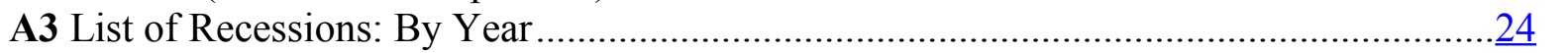

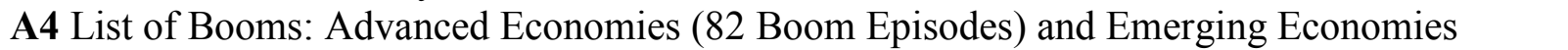

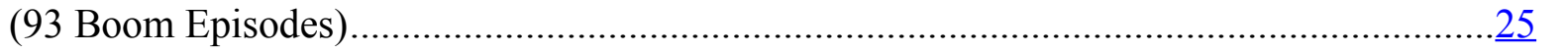

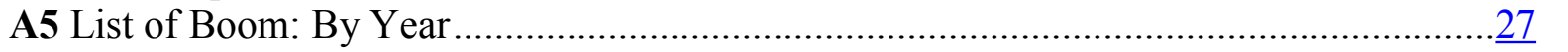
$\square$ 


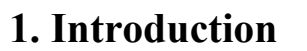

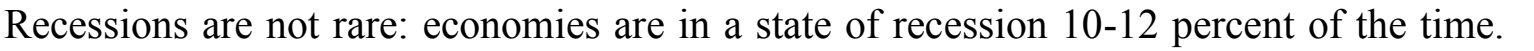

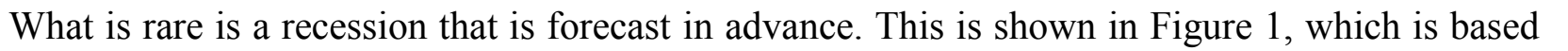

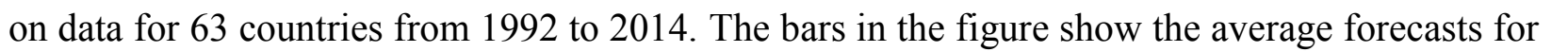
ए

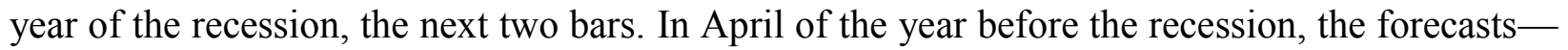

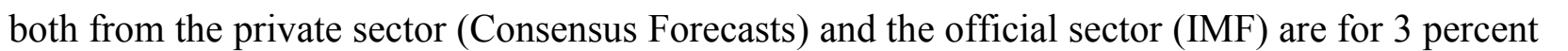

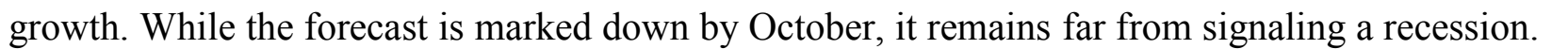

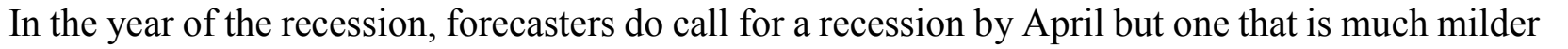

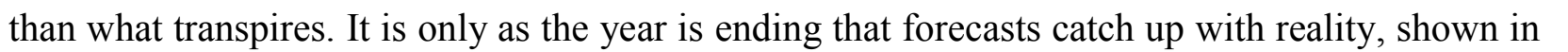

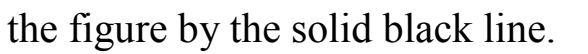

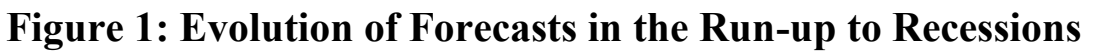

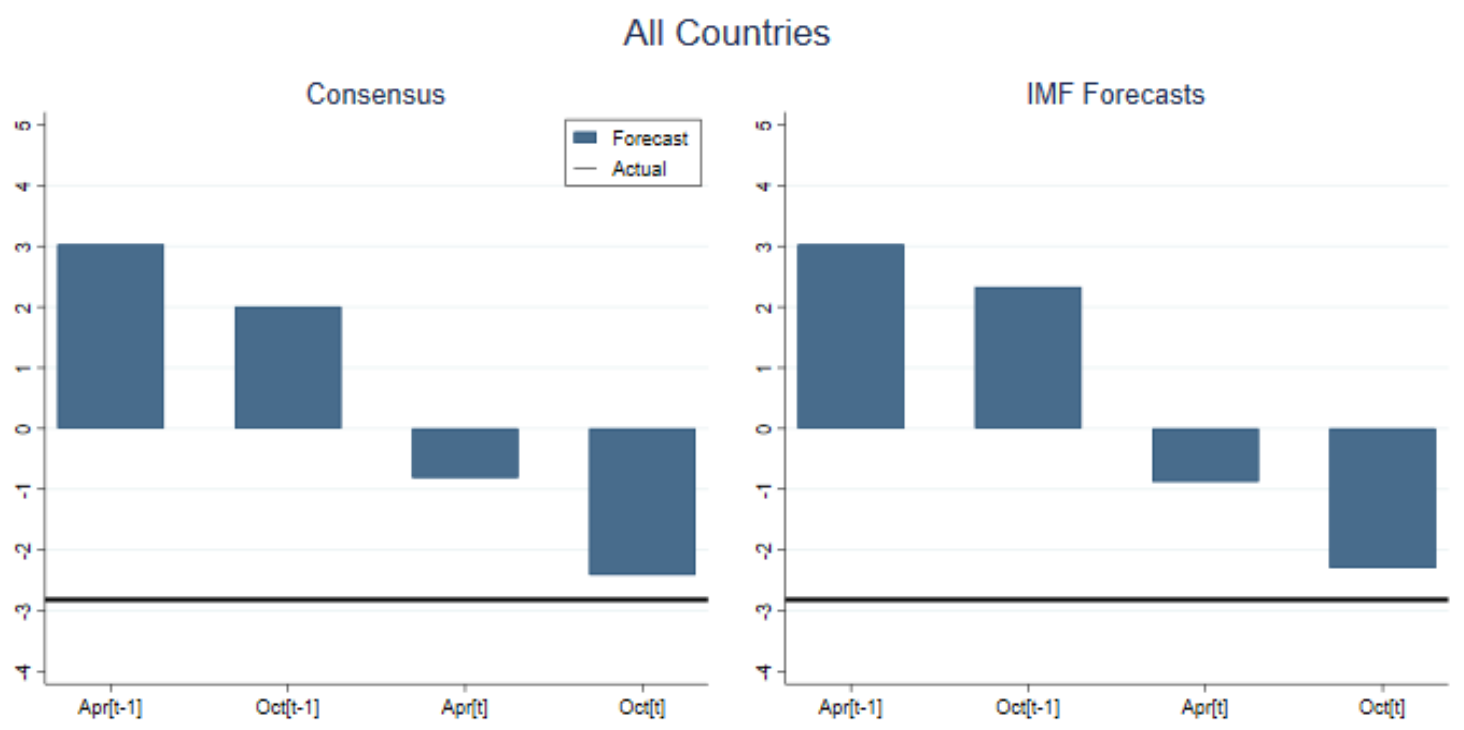

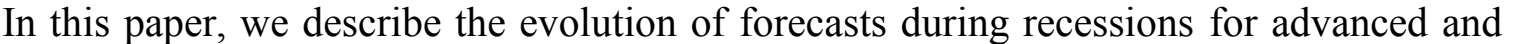

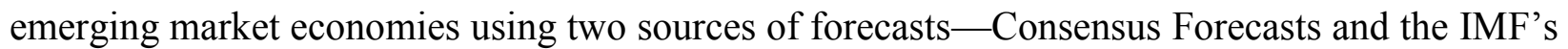

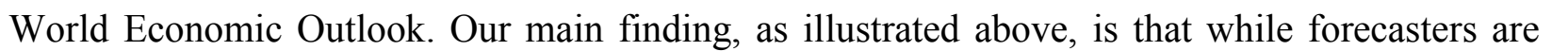

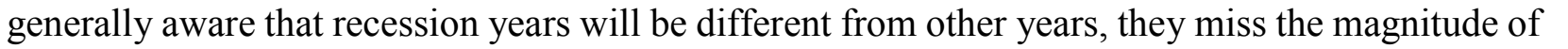
ए।

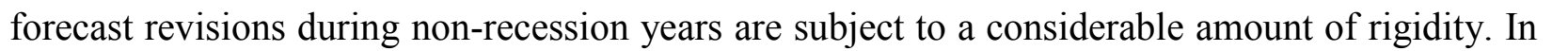

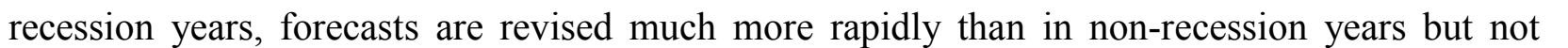




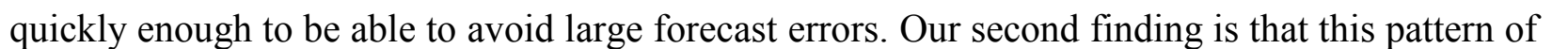

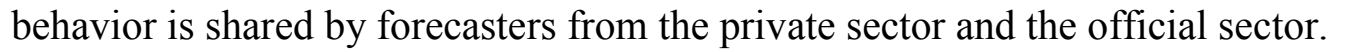

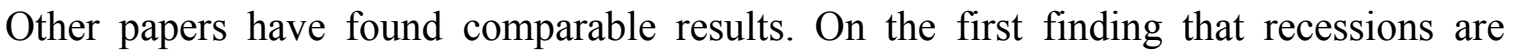

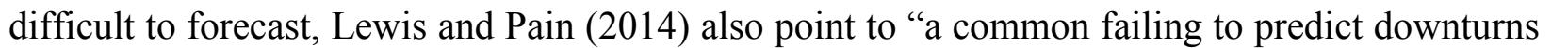

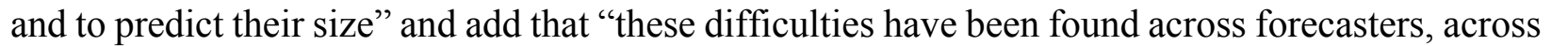

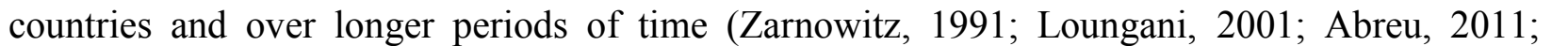

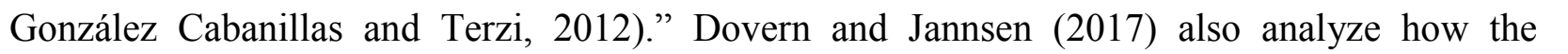

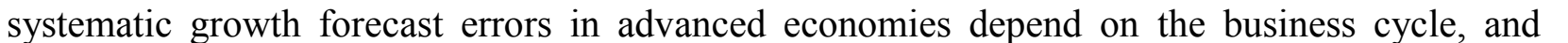

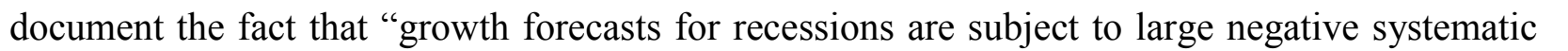
errors, while forecasts for recoveries are subject to small positive systematic errors."

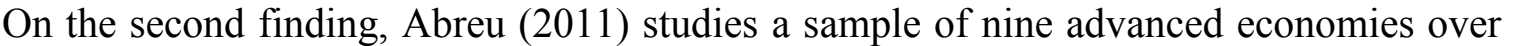

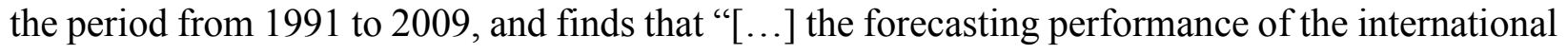

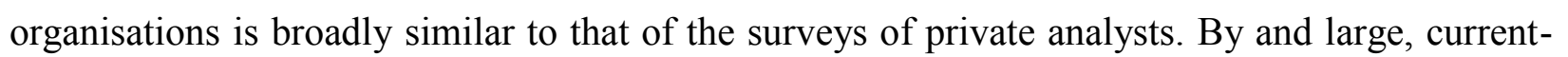

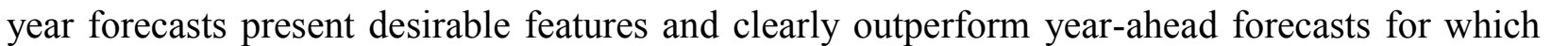
$\square \square \mid l$ ce is more mixed both in terms of quantitative and qualitative accuracy." $\square$

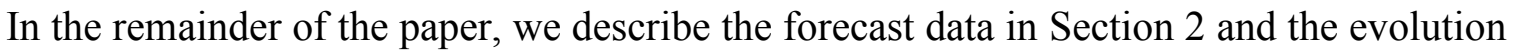

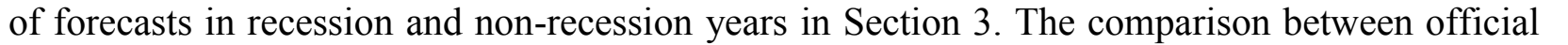

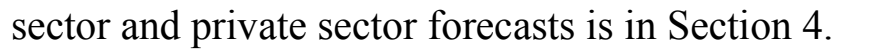

$\square$

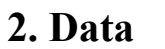

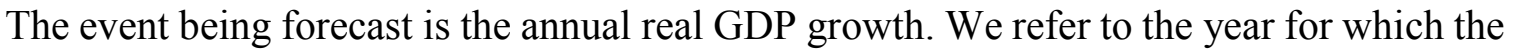

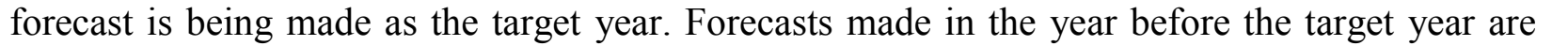

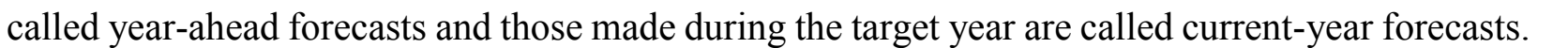

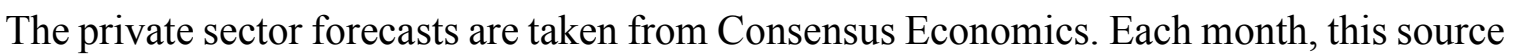

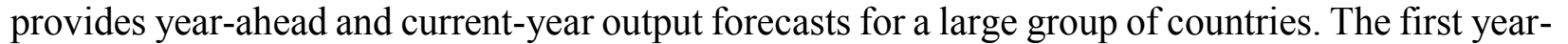

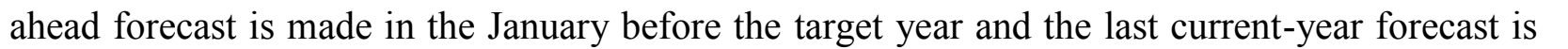

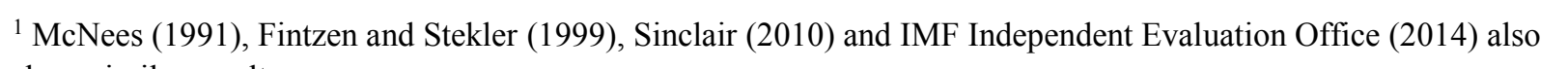

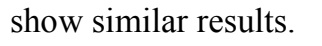




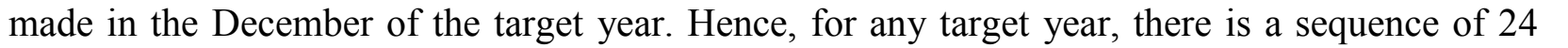

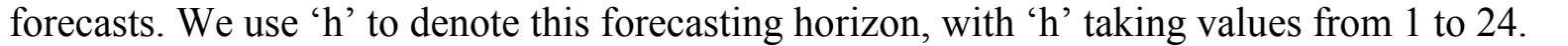
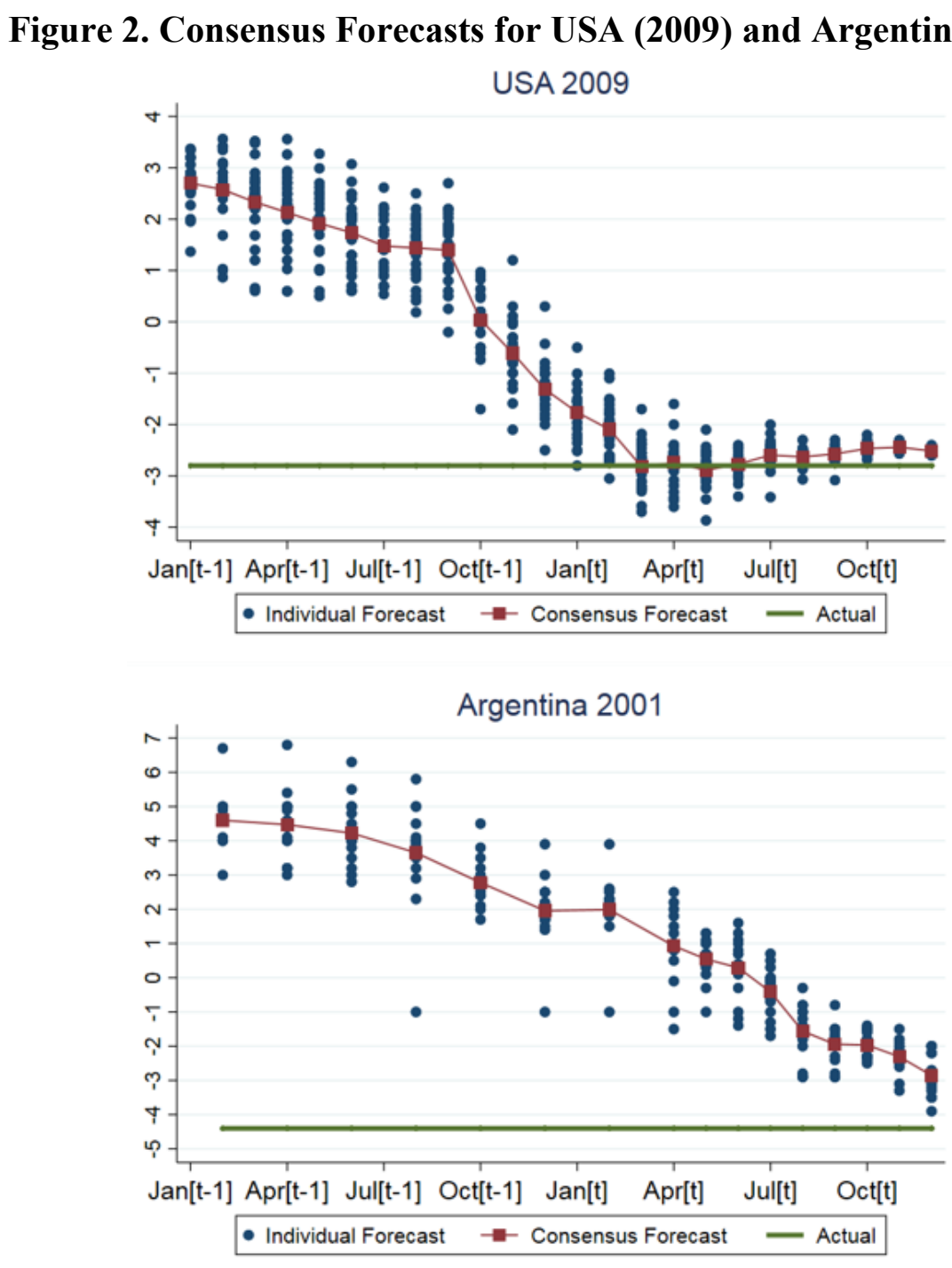

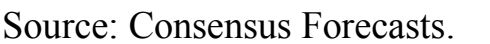

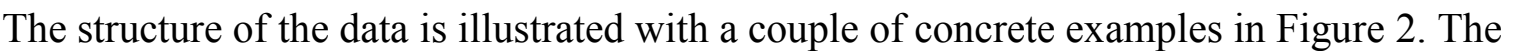

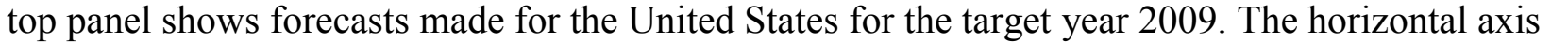

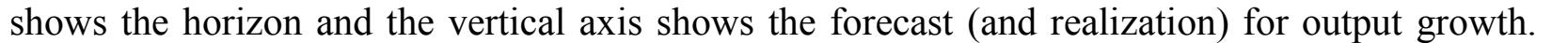

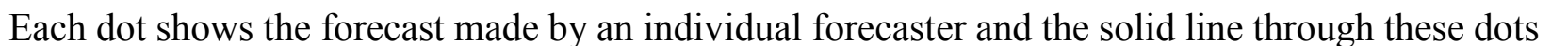
is the arithmetic average of these forecasts or the 'consensus'. In this paper, we use these consensus 


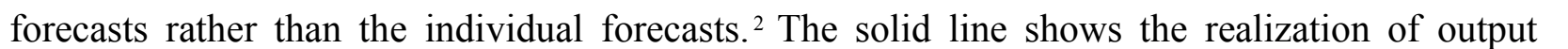

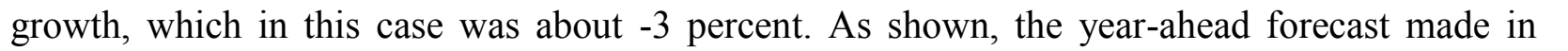

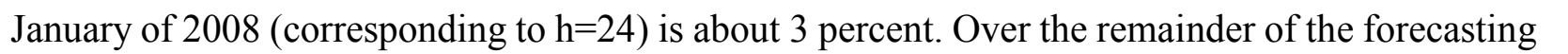

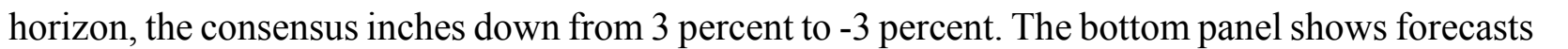
ए

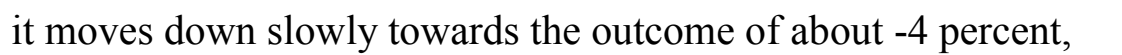

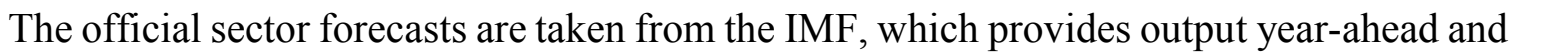

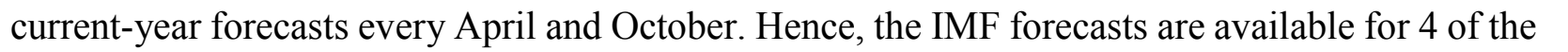

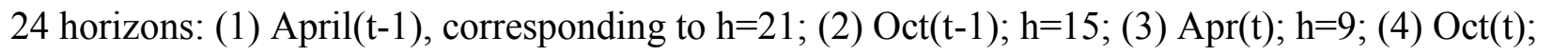
$\square \square \mathrm{m}$

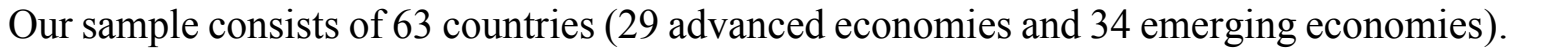

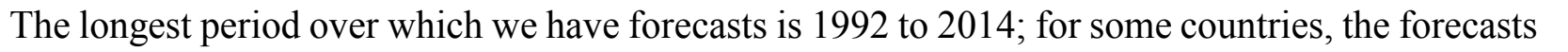

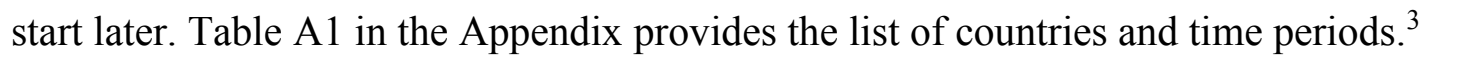

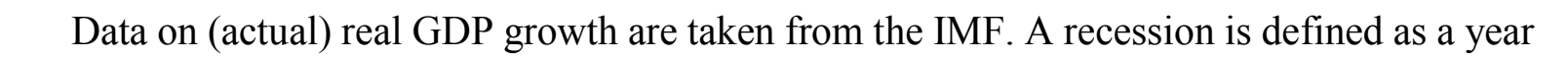

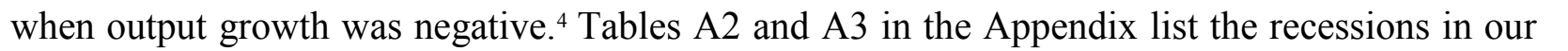

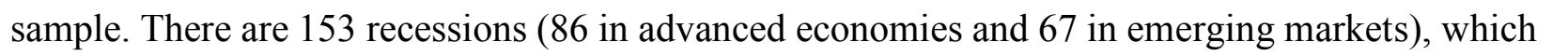

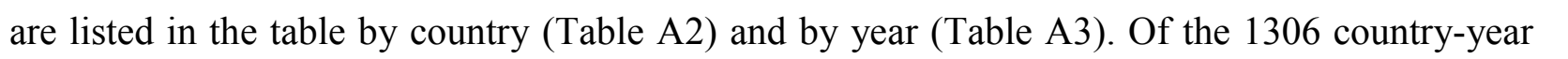

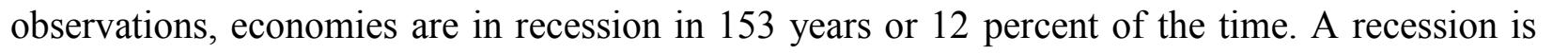

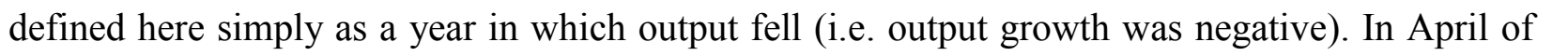
ए

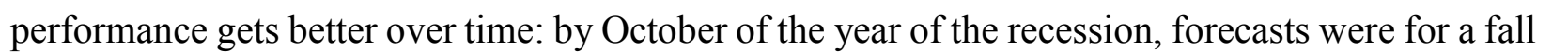

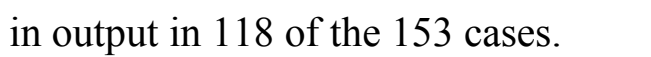

$\square$

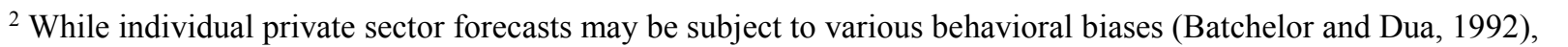

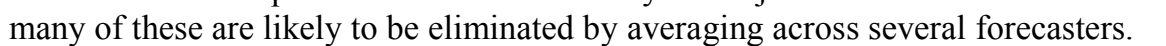

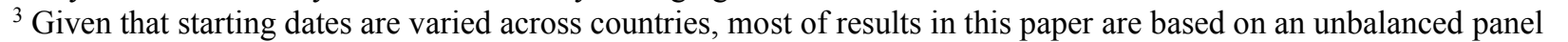

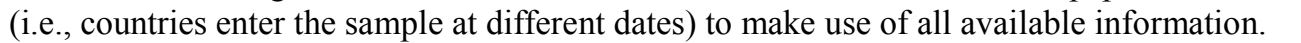

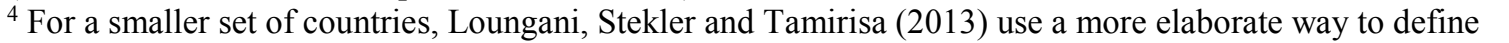

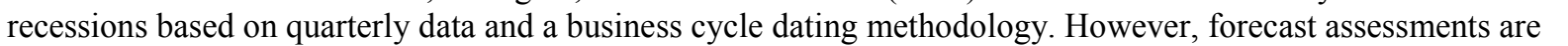

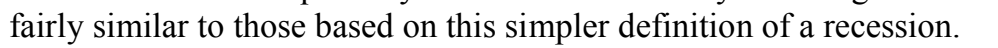




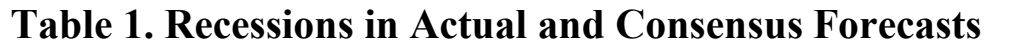

\begin{tabular}{|c|c|c|c|c|c|c|c|}
\hline$\square$ & $\square$ & \multicolumn{3}{|c|}{ 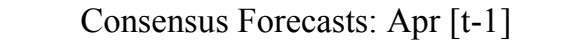 } & \multicolumn{3}{|c|}{ 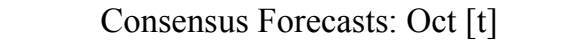 } \\
\hline$\square$ & $\square$ & 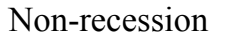 & 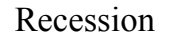 & प्राणा & 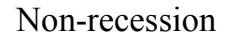 & 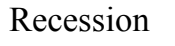 & प्या山 \\
\hline & 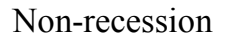 & $\square \longrightarrow \square$ & $\square$ & $\square \square \square$ & $\square \square \square$ & $\square$ & $\square \square \square$ \\
\hline$\square \square \square$ & 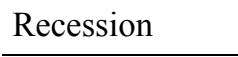 & $\square 1$ & $\square$ & $\square \square$ & $\square$ & $\square 1$ & $\square 1$ \\
\hline & 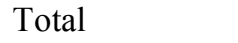 & $\square \sqcap \square$ & $\square$ & $\square \square \square$ & $\square \square \square$ & $\square \square$ & $\square \square \square$ \\
\hline
\end{tabular}

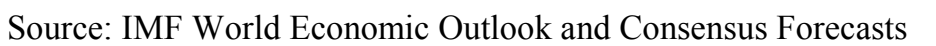

$\square$

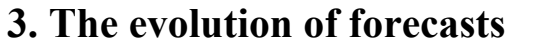

\subsection{Type 1 vs. Type 2 error}

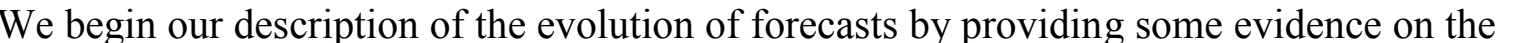

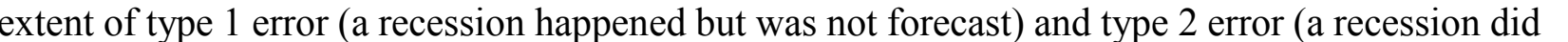

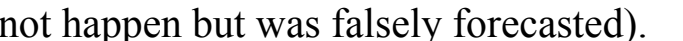

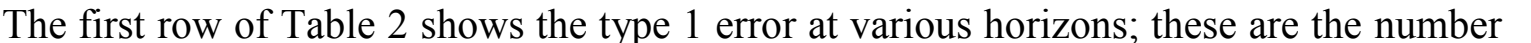

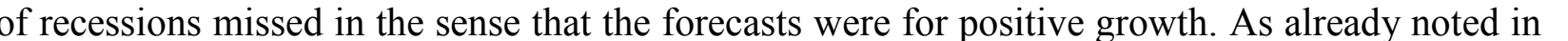

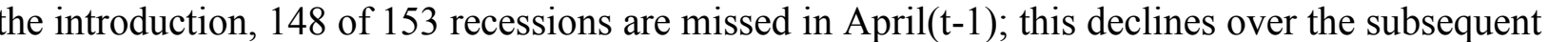

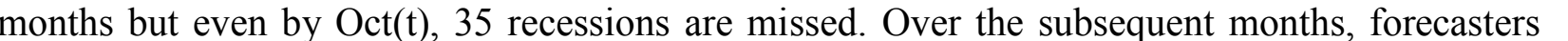

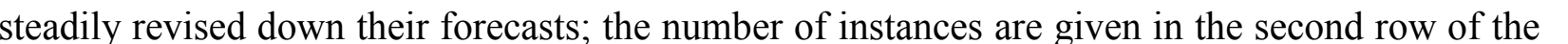
पाणाणाए

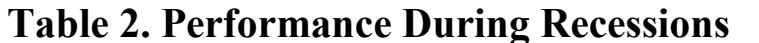

\begin{tabular}{|c|c|c|c|c|c|c|c|c|}
\hline 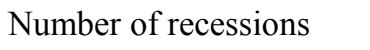 & \multicolumn{4}{|c|}{ 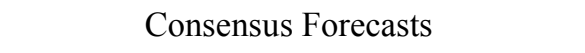 } & \multicolumn{4}{|c|}{ 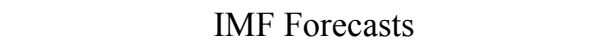 } \\
\hline 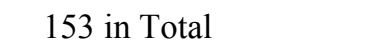 & $\square \square\|\| \square \square$ & 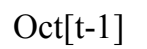 & 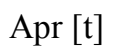 & 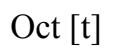 & $\square \square \| m \square \square$ & 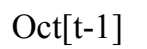 & 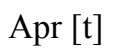 & 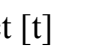 \\
\hline 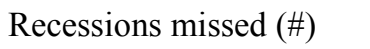 & $\square \square$ & $\square \square$ & $\square \square$ & $\square$ & $\square \square$ & $\square \square$ & $\square$ & $\square$ \\
\hline 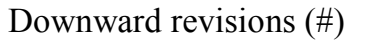 & $\square$ & $\square \square$ & $\square \square$ & $\square \square$ & $\square$ & $\square \square$ & $\square \square$ & $\square \square$ \\
\hline 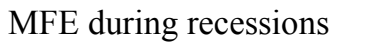 & $\square$ & $\square$ & $\square$ & $\square$ & $\square$ & $\square$ & $\square$ & $\square$ \\
\hline 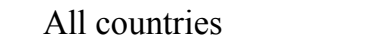 & एणा & एणा & एाए & एाए। & एण口 & एणाए & एाए। & एणा \\
\hline 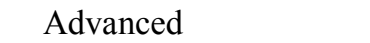 & एणा & एाण & एण口 & एाणा & एणा & एणा & एाणा & एण \\
\hline 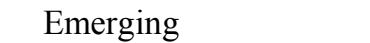 & एण口 & एाणा & एण口 & एाएा & एामा & एणाए & एाएा & एाणा \\
\hline
\end{tabular}

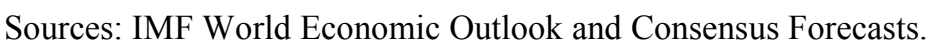

$\square$

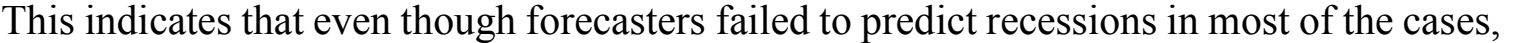
पा 


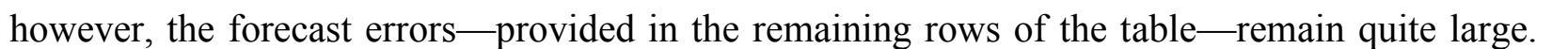

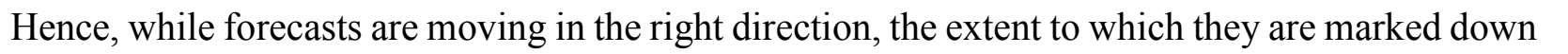

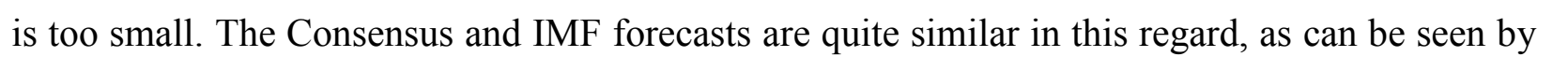

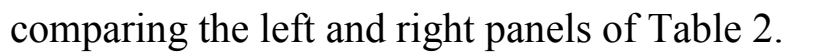

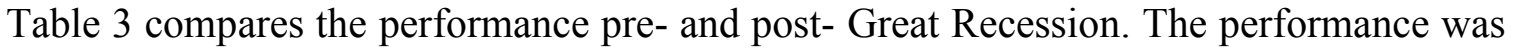

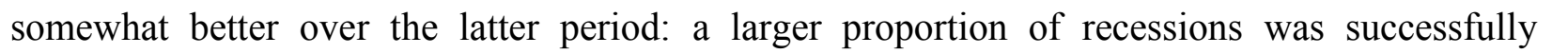

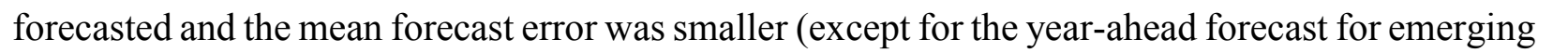

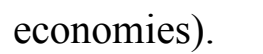

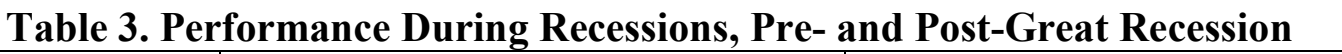

\begin{tabular}{|c|c|c|c|c|c|c|c|c|}
\hline 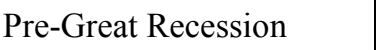 & \multicolumn{4}{|c|}{ 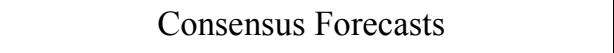 } & \multicolumn{4}{|c|}{ 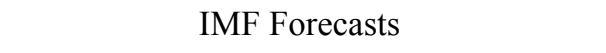 } \\
\hline 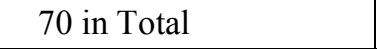 & $\square \square\|\|\|\|$ & 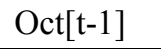 & 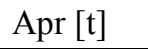 & 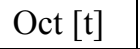 & $\square \square\|\| \| \amalg$ & 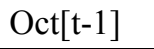 & $\square \square\|\|$ & 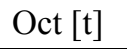 \\
\hline 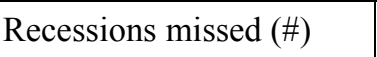 & $\square$ & $\square$ & $\square$ & $\square$ & $\square \square$ & $\square \square$ & $\square$ & $\square$ \\
\hline 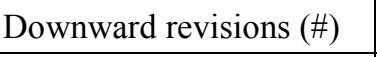 & $\square$ & $\square \square$ & $\square \square$ & $\square \square$ & $\square$ & $\square \square$ & $\square$ & $\square \square$ \\
\hline 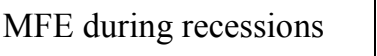 & $\square$ & $\square$ & $\square$ & $\square$ & $\square$ & $\square$ & $\square$ & $\square$ \\
\hline 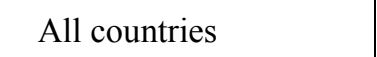 & घणम & घणम & एणा & पाणाए & घणम & एणा & एाणा & घणम \\
\hline 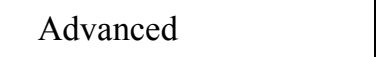 & एणा & घणा & एणा & एणाए & घणाए & एणा & एणा & एणा \\
\hline 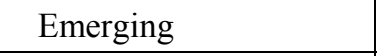 & पाए & पाणा & एाए। & पाणाए & पाणा & एणा & एाणाए & पाएा \\
\hline 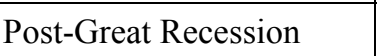 & \multicolumn{4}{|c|}{ 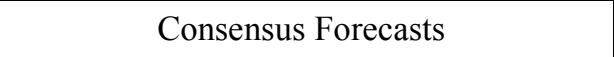 } & \multicolumn{4}{|c|}{ 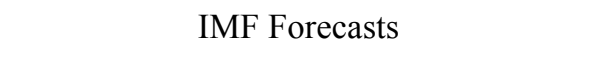 } \\
\hline 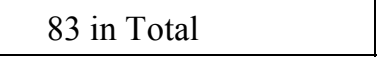 & $\square \square\|\|\|\|$ & 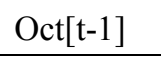 & 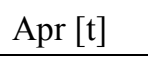 & 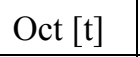 & $\square \square\|\| \square \square$ & 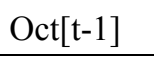 & $\square \square\|\|$ & 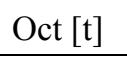 \\
\hline 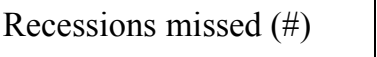 & $\square$ & $\square \square$ & $\square \square$ & $\square \square$ & $\square$ & $\square$ & $\square$ & $\square \square$ \\
\hline 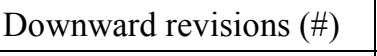 & $\square$ & $\square$ & $\square$ & $\square \square$ & $\square$ & $\square \square$ & $\square$ & $\square \square$ \\
\hline 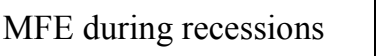 & $\square$ & $\square$ & $\square$ & $\square$ & $\square$ & $\square$ & $\square$ & $\square$ \\
\hline 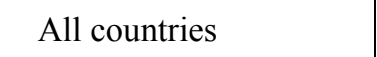 & एाण & एाए & एणा & पाणाए & एणा & एणा & $\square$ & पाए \\
\hline एயण口माया & एणा & एण口 & एण口 & घणाए & एण口 & एणा & एणाए & एण口 \\
\hline एणामाणामा & घणम & एण口 & एणा & 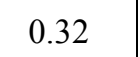 & एणा & पाणा & पाणाए & $\square \square$ \\
\hline
\end{tabular}

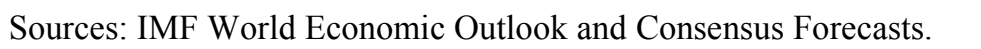

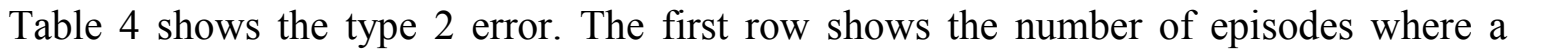

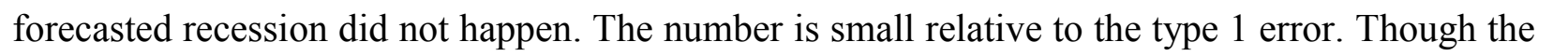

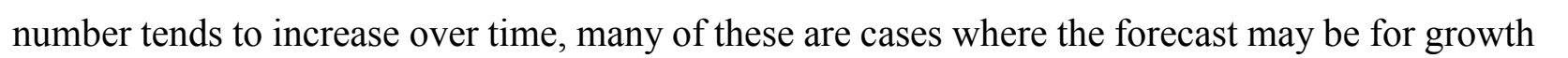

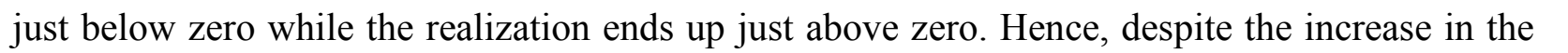

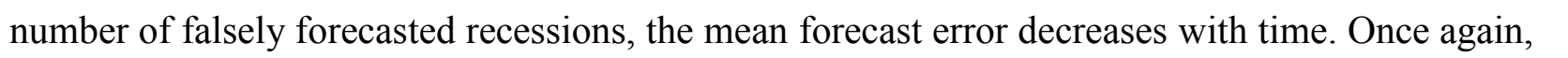

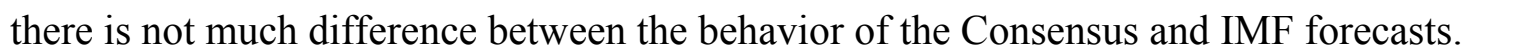




\begin{tabular}{|c|c|c|c|c|c|c|c|c|}
\hline$\square$ & \multicolumn{4}{|c|}{ 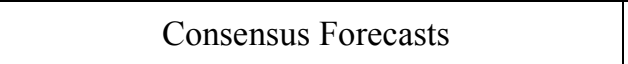 } & \multicolumn{4}{|c|}{ 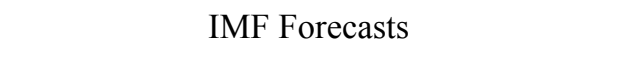 } \\
\hline$\square$ & $\square \square\|\| ा \mid \mathbb{I}$ & 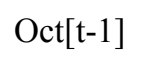 & $\square \square \square$ & 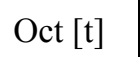 & $\square \square\|\| ा \mid \mathbb{I}$ & 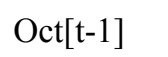 & $\square \square \|$ & $\square \square$ पा山ा山ा \\
\hline 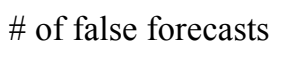 & $\square$ & $\square \square$ & $\square$ & $\square$ & $\square$ & $\square$ & $\square$ & $\square$ \\
\hline 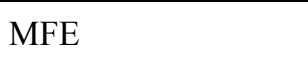 & $\square$ & $\square$ & $\square$ & $\square$ & $\square$ & $\square$ & $\square$ & $\square$ \\
\hline 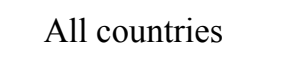 & $\square \square$ & $\square \square$ & $\square \square \square$ & $\square \mathrm{पाए}$ & $\square \square$ & $\square \square$ & $\square \mathrm{पाए}$ & $\square \square$ \\
\hline யயாயாणा & $\square \square$ & $\square ण$ & एणा & $\square ण$ & $\square ण$ & $\square \square$ & 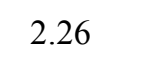 & पणा \\
\hline एणामणणाण & $\square \square \square$ & $\square \square$ & $\square \square \square$ & $\square ण \square$ & $\square \square \square$ & $\square \square$ & $\square \square$ & $\square \square$ \\
\hline
\end{tabular}

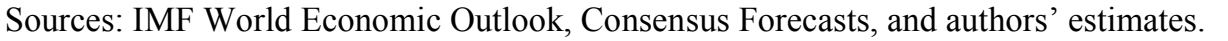

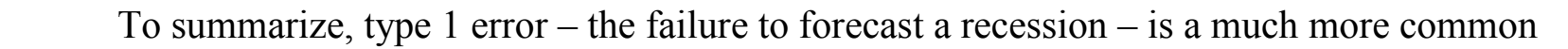

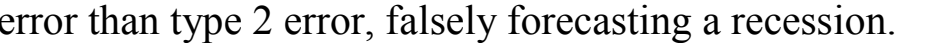

\subsection{Comparing Recessions and Non-Recession Years}

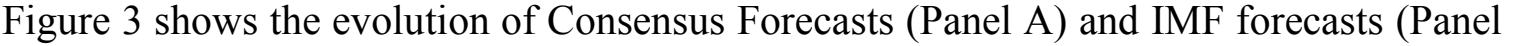

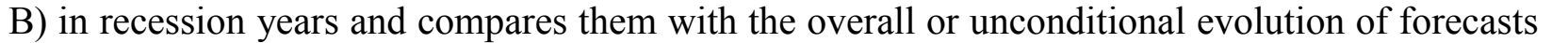
ए

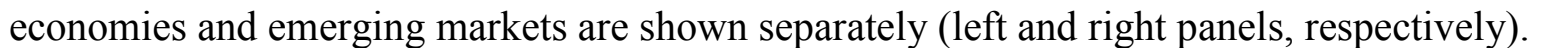




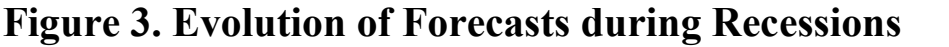
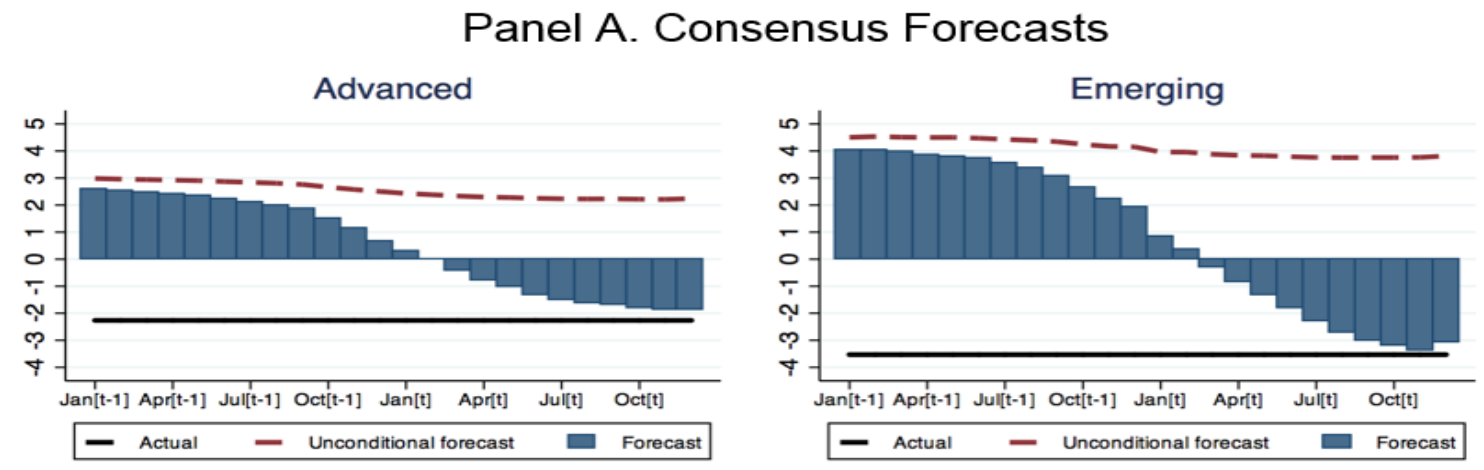

Panel B. IMF Forecasts
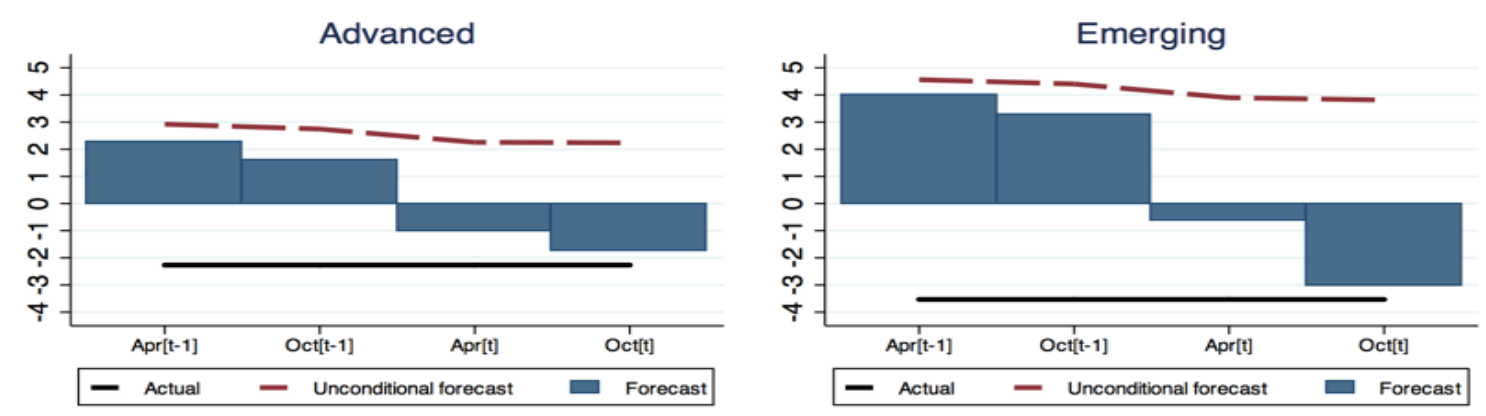

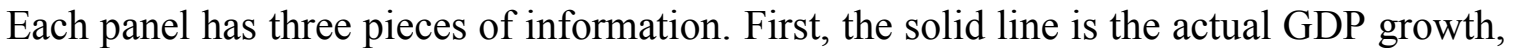

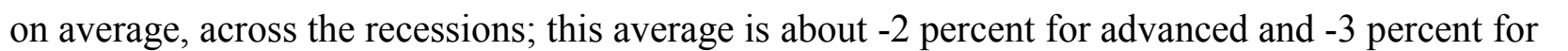

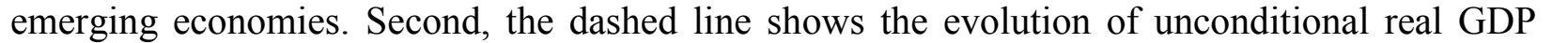

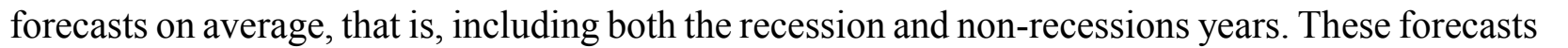

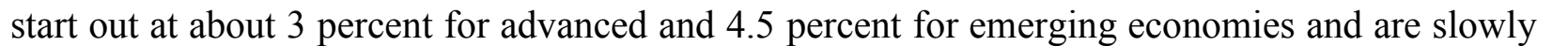

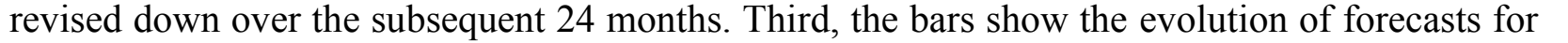

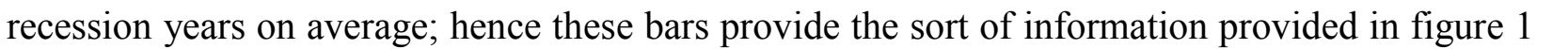

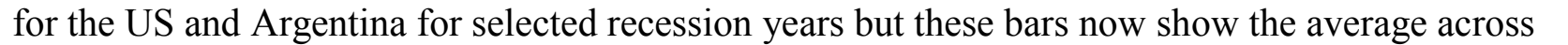

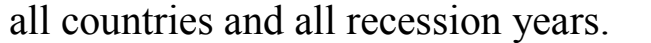

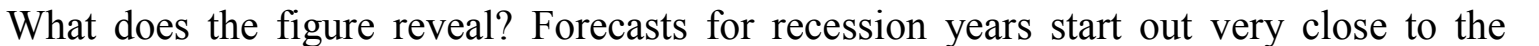

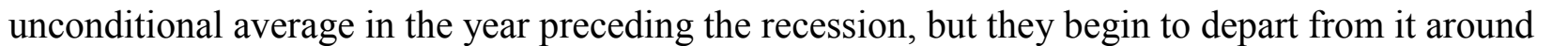
ए

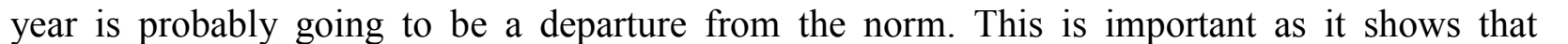

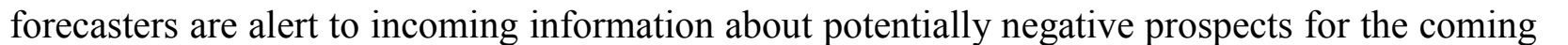




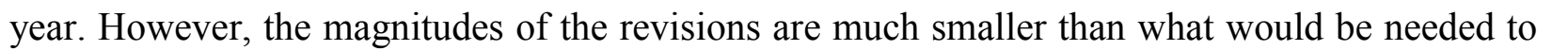

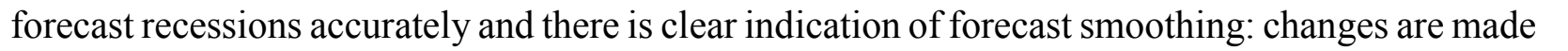

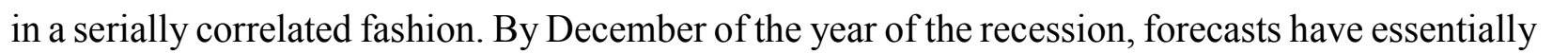

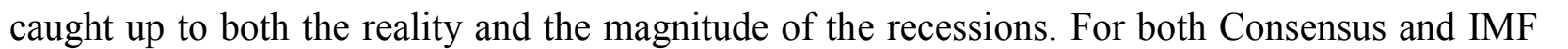

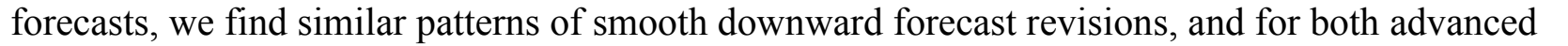

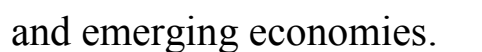

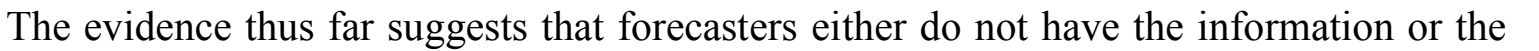
ए

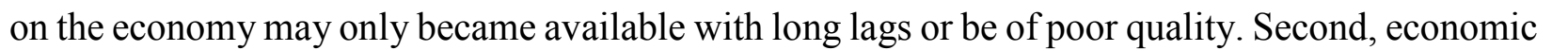

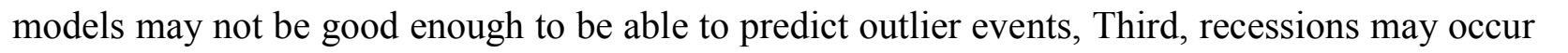

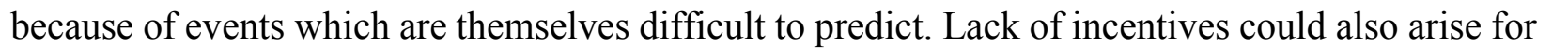

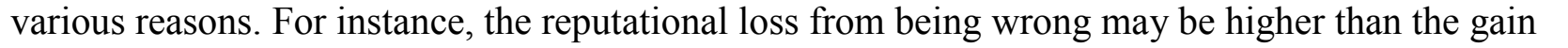

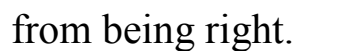

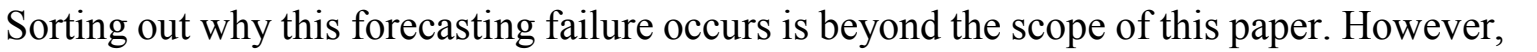

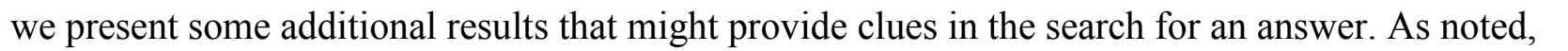

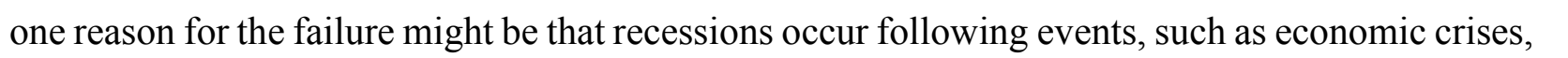

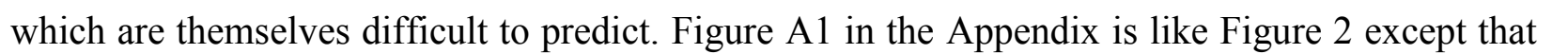

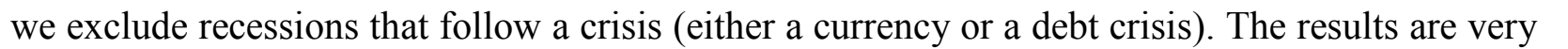
ए

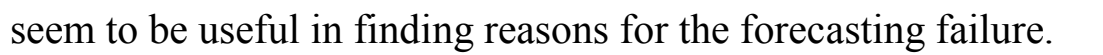

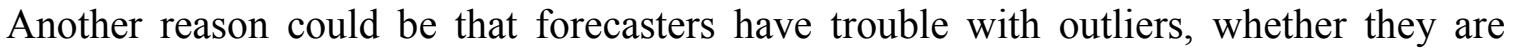

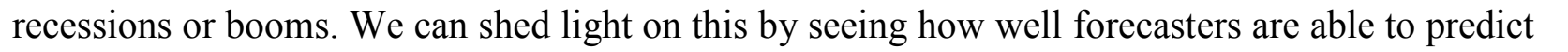

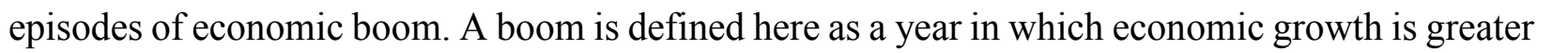

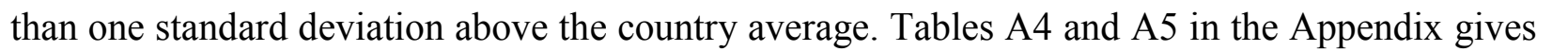

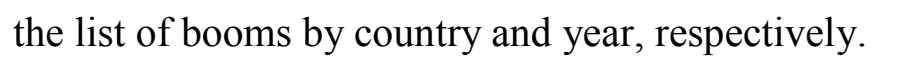

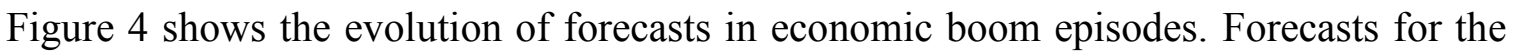

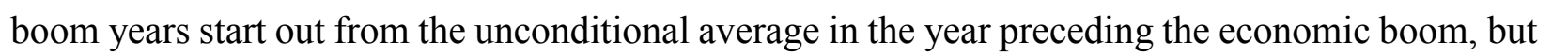

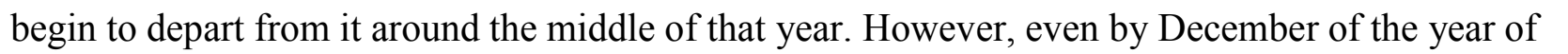

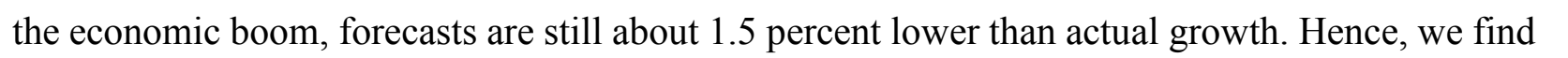

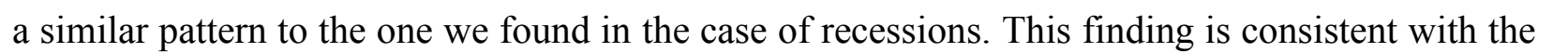

11

CInternational Monetary Fund. Not for Redistribution 


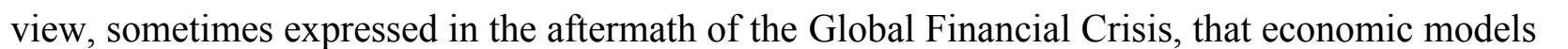

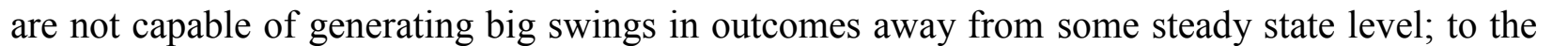

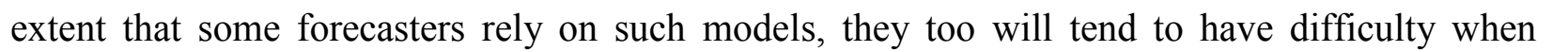

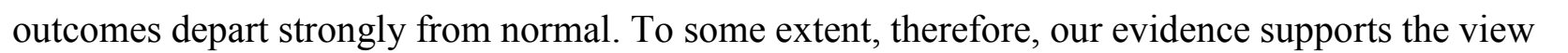
पा

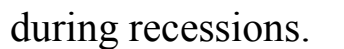

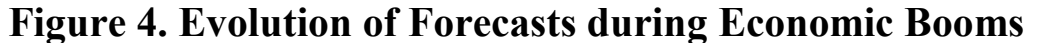

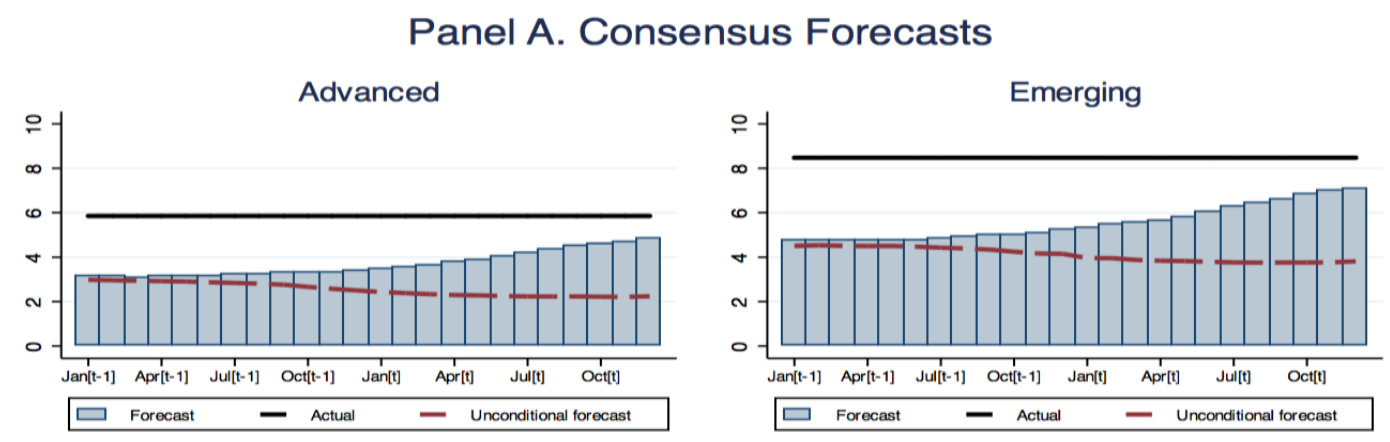

Panel B. IMF Forecasts
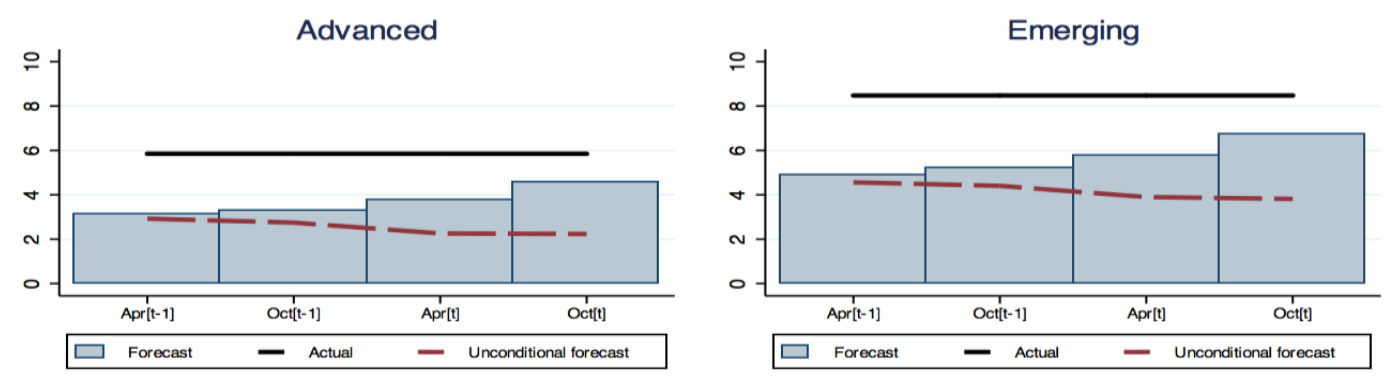

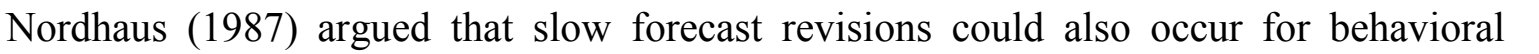

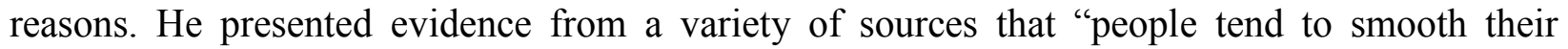

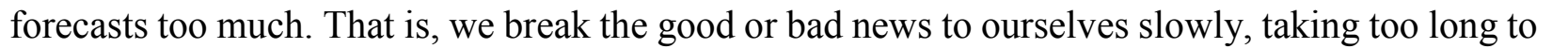
allow surprises to be incorporated into our forecasts." $\square$ 


\subsection{Information rigidity around turning points $\square$}

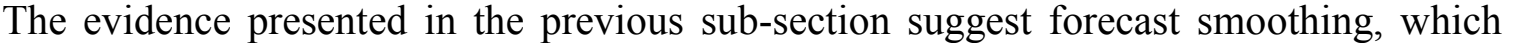

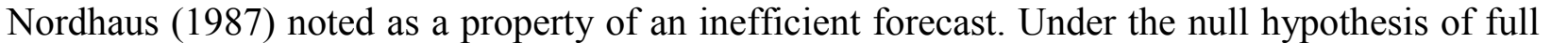

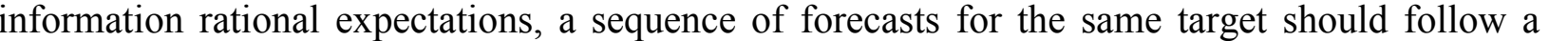

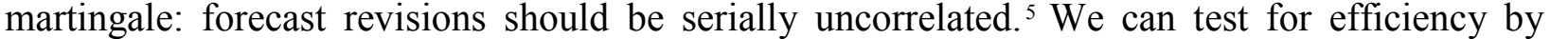

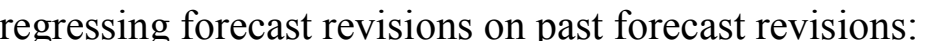

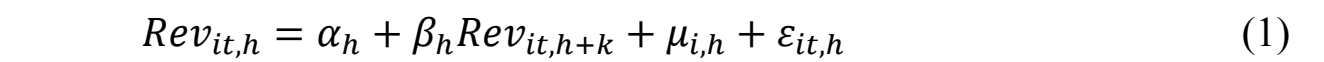

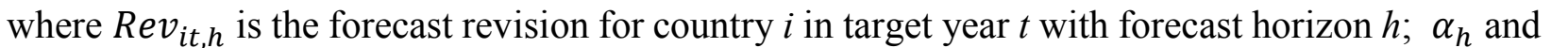

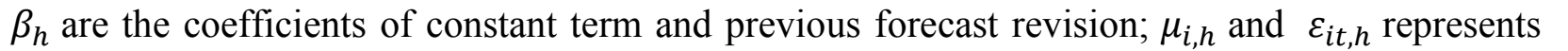

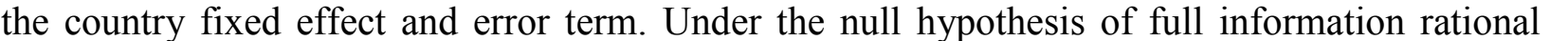

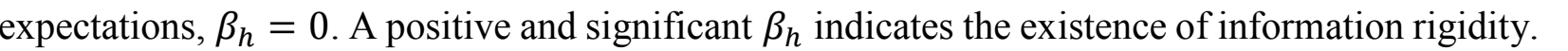

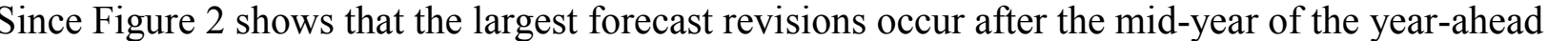

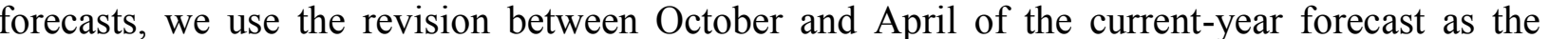

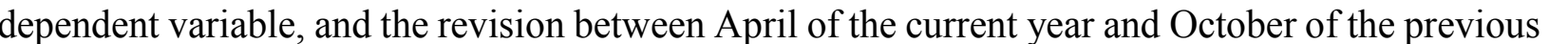

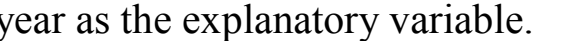

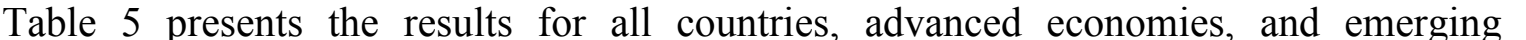

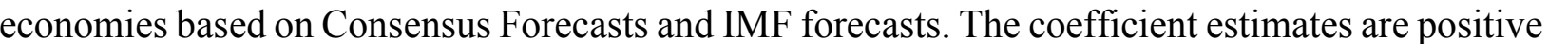

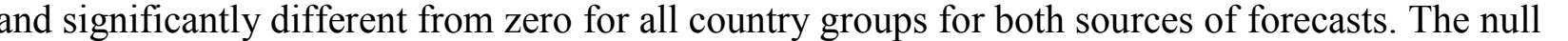

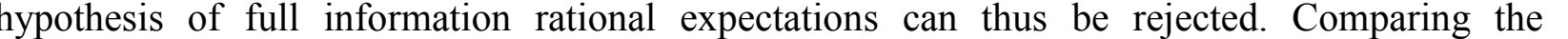

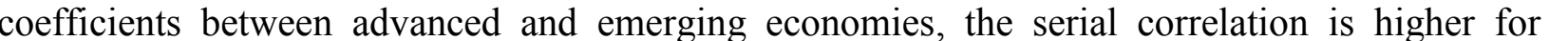

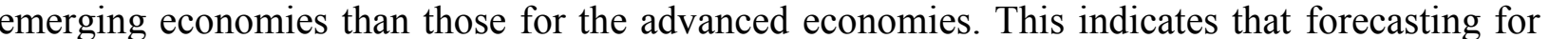

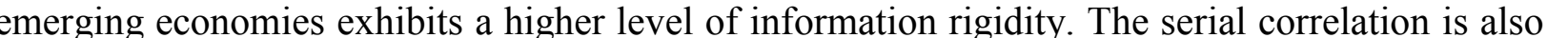

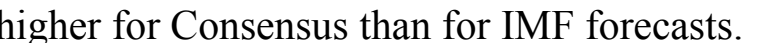

$\square$

$\square$

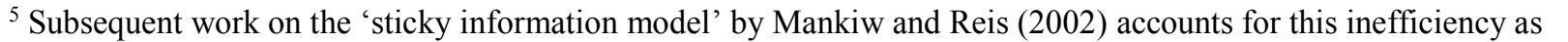

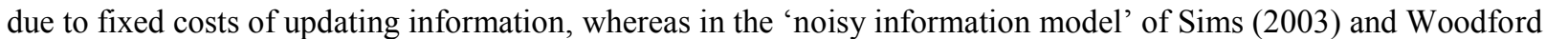
घम

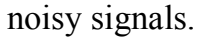

13

CInternational Monetary Fund. Not for Redistribution 


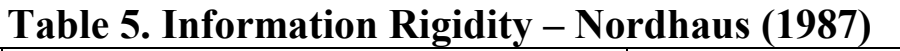

\begin{tabular}{|c|c|c|c|c|c|c|}
\hline 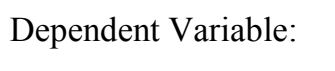 & $\square$ & $\square \square \mid\|1\| \square \square$ & $\square$ & $\square$ & $\mathbb{\square} \square \square$ & $\square$ \\
\hline पमाणाए & $\square \square$ & $\square \square \prod 11 \square$ & प्वाणाण & $\square \square$ & $\square \square 111 \square$ & 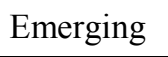 \\
\hline 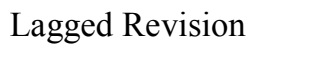 & $\square \square \square \square$ & $\square \square \square \square$ & $\square \square \square \square \square$ & $\square \square \square \square$ & $\square \square$ & $\square \square \square \square$ \\
\hline$\square$ & एणाण & एणाण & पाणाण & एणाण & एणाण & एणाण \\
\hline 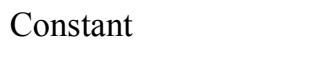 & $\square \square \square \square$ & पणाए & 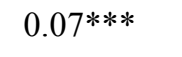 & एणПए & पाए & 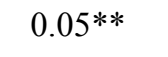 \\
\hline$\square$ & एवाण & एणाए & एाயा & एயாण & एणाய & एवाणा \\
\hline 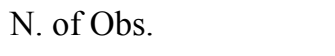 & $\square \square \square$ & $\square \square$ & $\square \square$ & $\square П \square$ & $\square \square$ & $\square \square$ \\
\hline$\square \square \square$ & $\square \square \square$ & $\square \square$ & $\square \square$ & $\square \square$ & $\square \square$ & $\square \square$ \\
\hline
\end{tabular}

Source: IMF World Economic Outlook, Consensus Forecasts, and authors’ estimates. $\mathbb{D}$

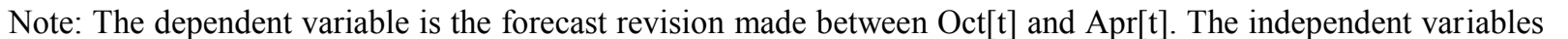

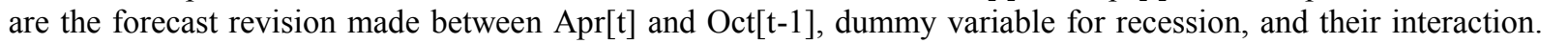

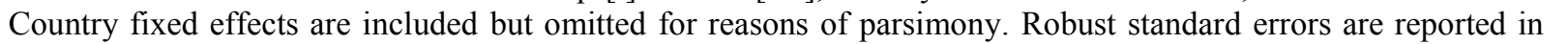

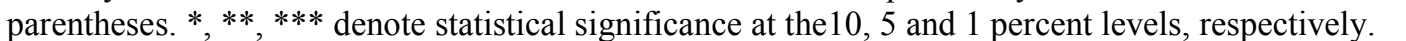

$\square$

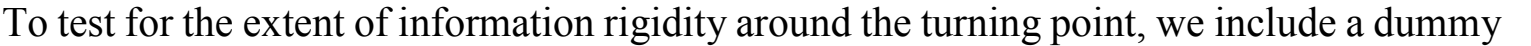

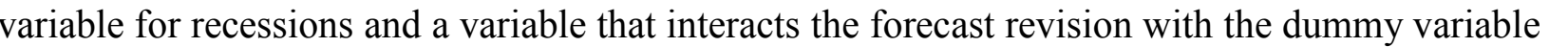

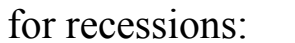

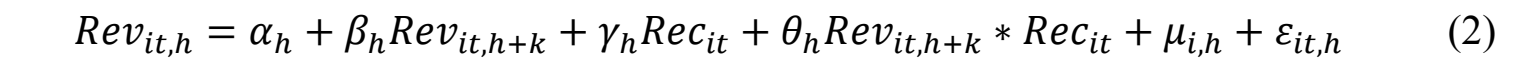

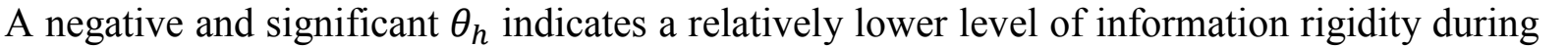

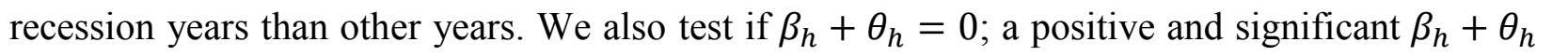
ए।

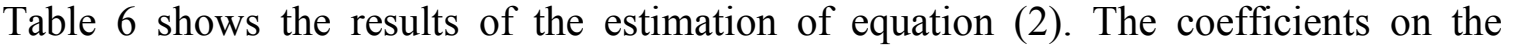

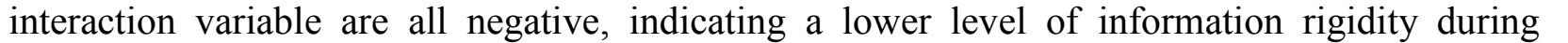

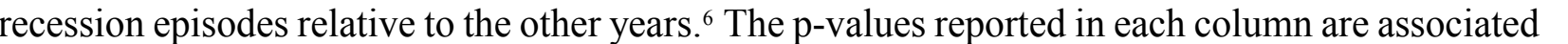

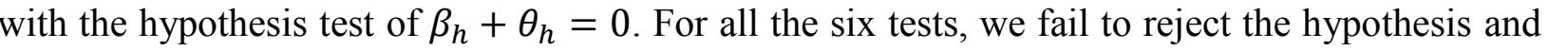

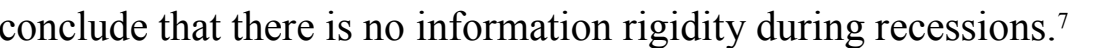

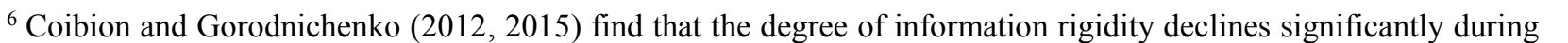

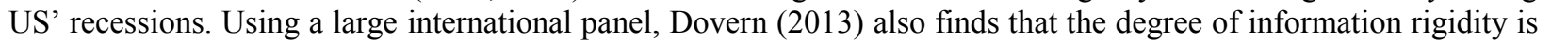

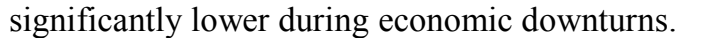

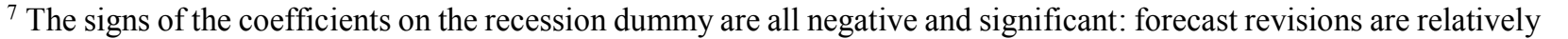

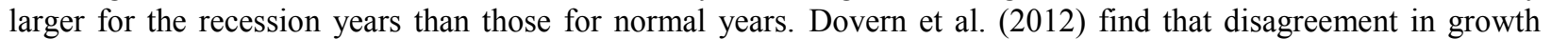

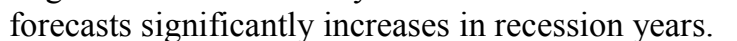

14

CInternational Monetary Fund. Not for Redistribution 


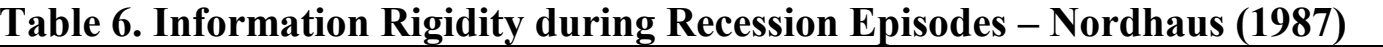

\begin{tabular}{|c|c|c|c|c|c|c|}
\hline 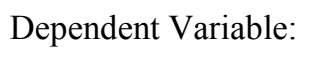 & $\square$ & $\square \square \| \square \square \square$ & $\square$ & $\square$ & $\mathbb{\square \square}$ & $\square$ \\
\hline पवाणाए & $\square \square$ & $\square \square \prod \prod म$ & पणाणाए & $\square$ 血 & पाएाए & पणपाणए \\
\hline 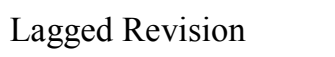 & $\square ण 11 \square$ & 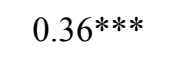 & पामाए & पामाए & 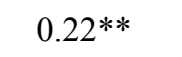 & $\square \mathrm{पाए}$ \\
\hline$\square$ & पाणाण & पाणाण & 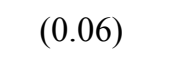 & पाणाण & एणाण & एणाण \\
\hline 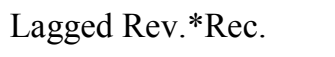 & एणाए & पाण & एणाए & एण口 & एणमा & पणाए \\
\hline$\square$ & एणाயण & एणाएण & पाणाण & एणाய & एயாய & एणाएण \\
\hline पणाயणम & एणमाए & एणमा & एणामए & एणामाए & पाणाम & एणामा \\
\hline$\square$ & एणाणा & एणाण & एणाण & पाणाण & पाणाण & एणाए \\
\hline 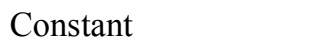 & 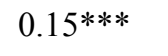 & 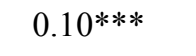 & पामाए & 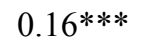 & 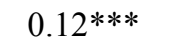 & 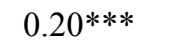 \\
\hline$\square$ & एणाएण & एणाएण & पणाणा & पाणाण & एणा & एणाए \\
\hline 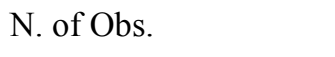 & $\square \square \square$ & $\square \square$ & $\square$ & $\square \square \square$ & $\square \square$ & $\square \square$ \\
\hline$\square \square \square$ & $\square \square \square$ & $\square \square$ & $\square \square$ & $\square \square$ & $\square \square$ & 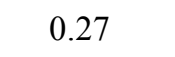 \\
\hline पणमाण & $\square \square \square$ & $\square \square$ & $\square \square$ & 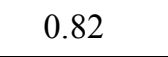 & $\square \mathrm{पाए}$ & एणा। \\
\hline
\end{tabular}

Source: IMF World Economic Outlook, Consensus Forecasts, and authors’ estimates.

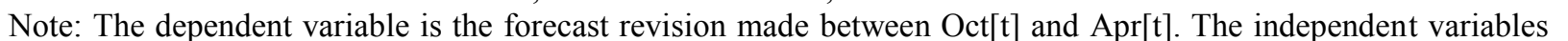

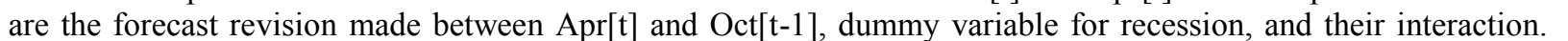

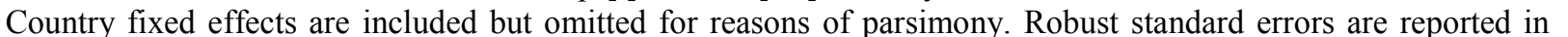

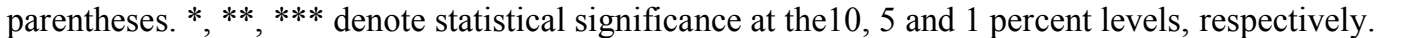

$\square$

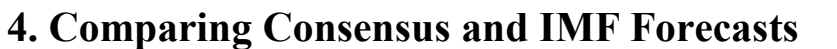

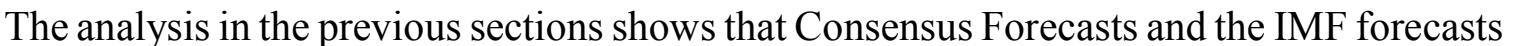

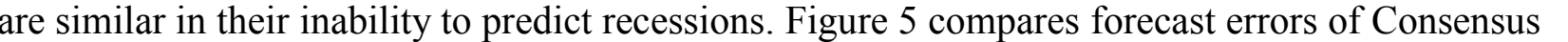

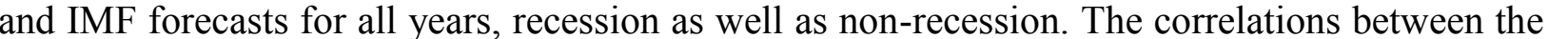

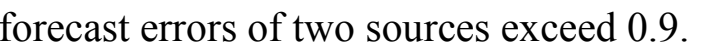

15

CInternational Monetary Fund. Not for Redistribution 


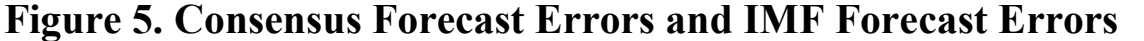
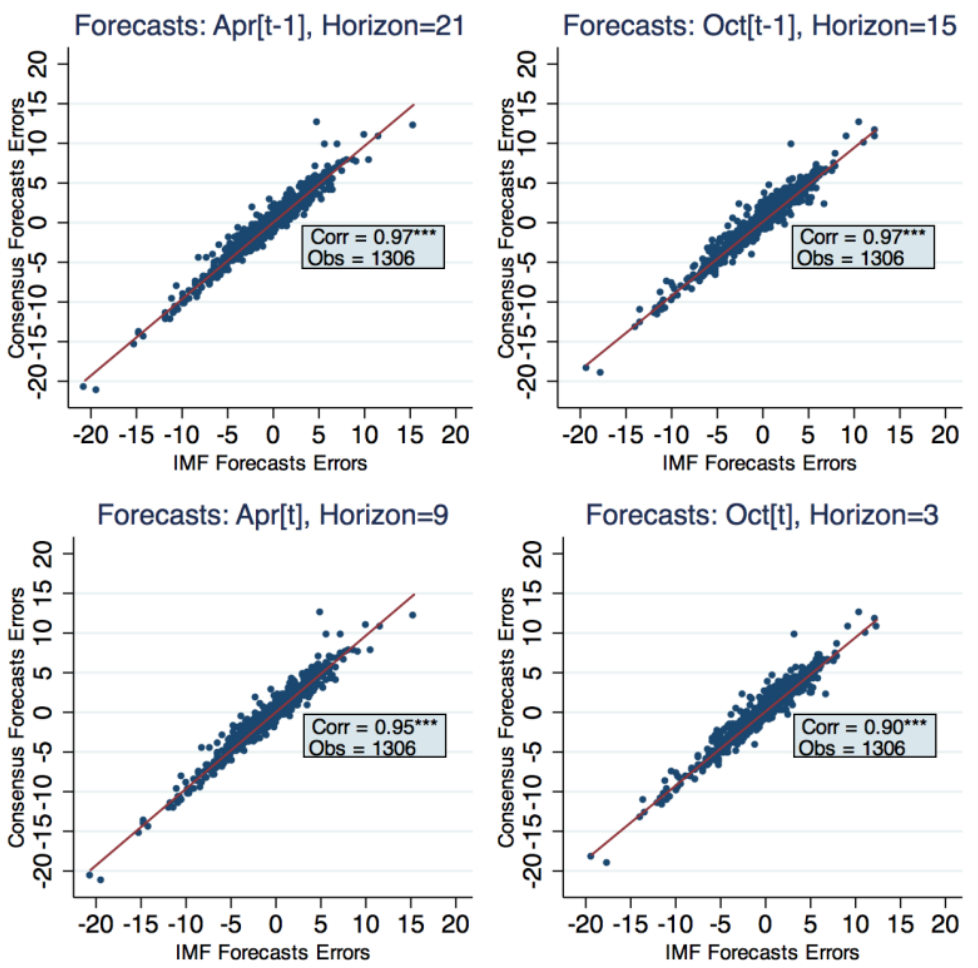

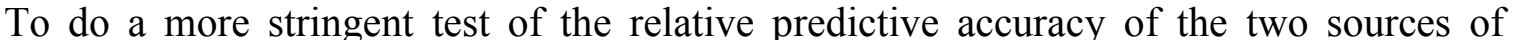

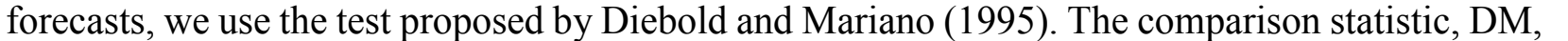

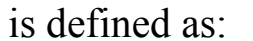

$$
D M=H^{-1 / 2} \frac{\sum_{j=1}^{H} d_{j}}{\sigma_{d}} \rightarrow N(0,1) \square
$$

$\square \square \square\|\|$

$$
d_{j}=g\left(e_{1 j}\right)-g\left(e_{2 j}\right) \square
$$

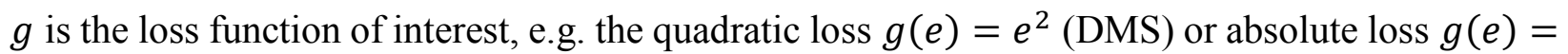

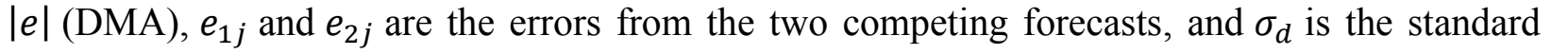

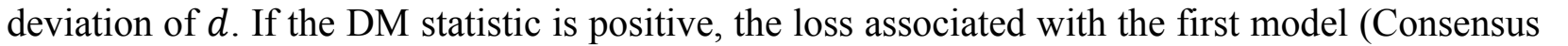

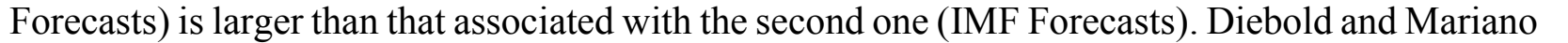

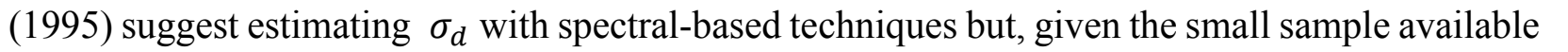

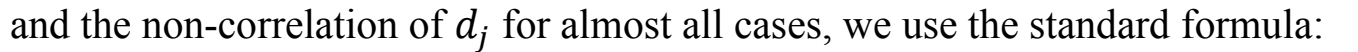




$$
\hat{\sigma}_{d}=\frac{1}{H-1} \sum_{j=1}^{H}\left(d_{j}^{-1} H \sum_{i=1}^{H} d_{i}\right)^{2} \square
$$

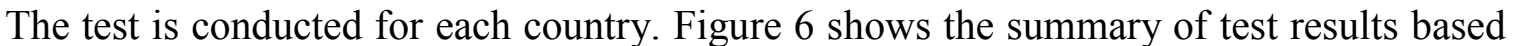

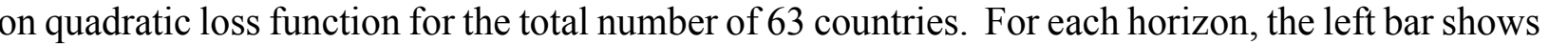

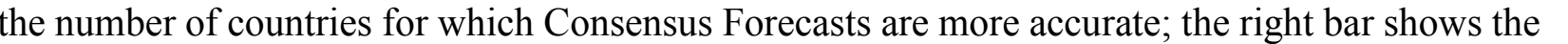

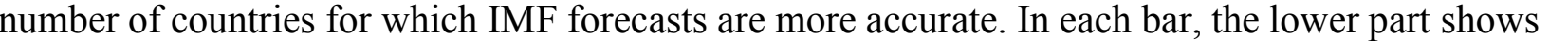

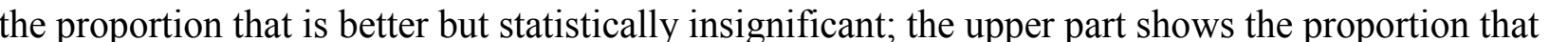

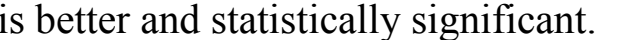

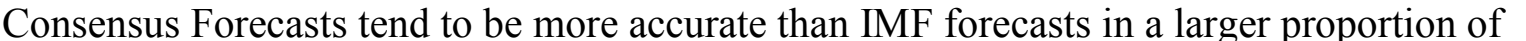

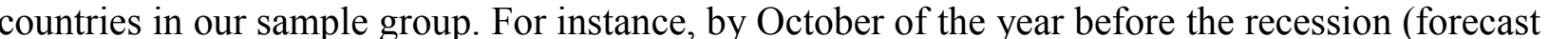

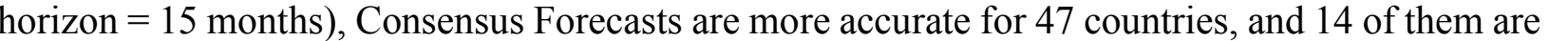

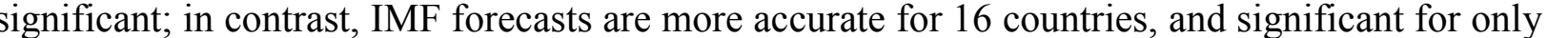

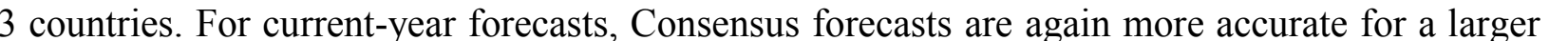

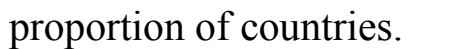

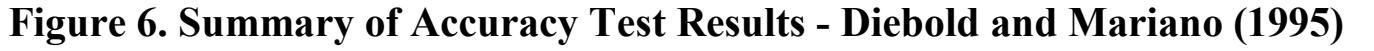

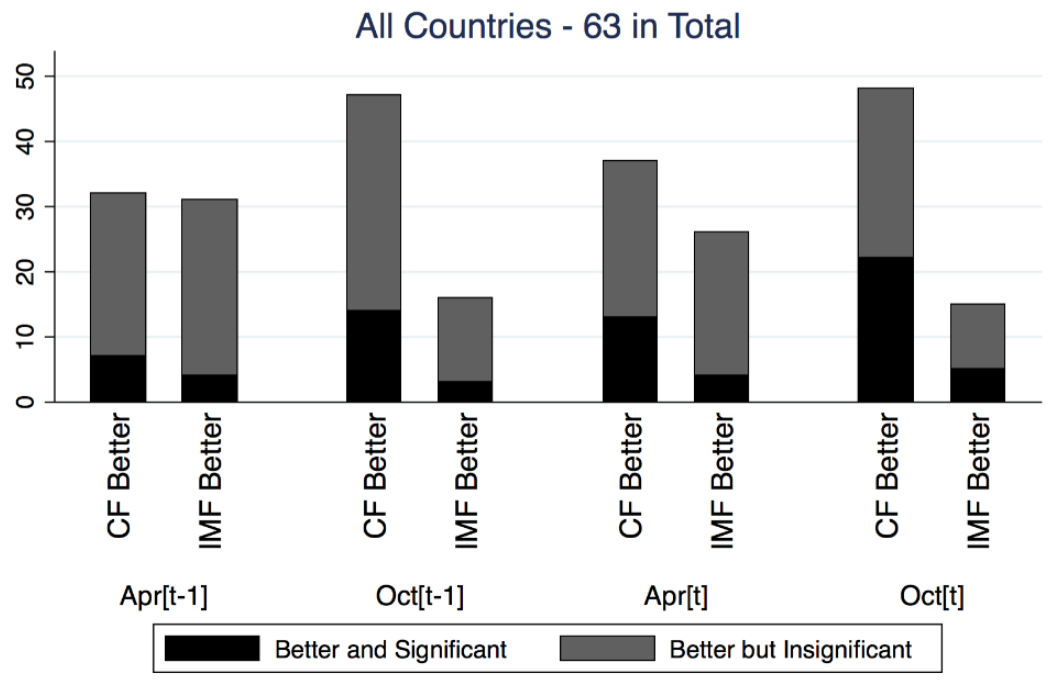

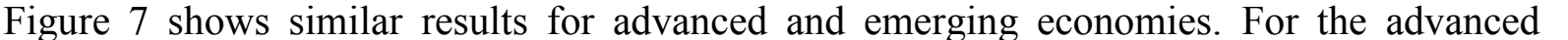

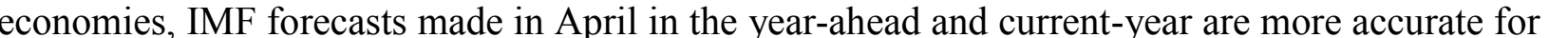




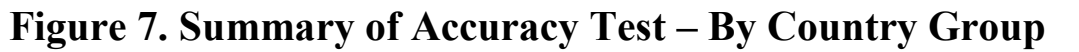
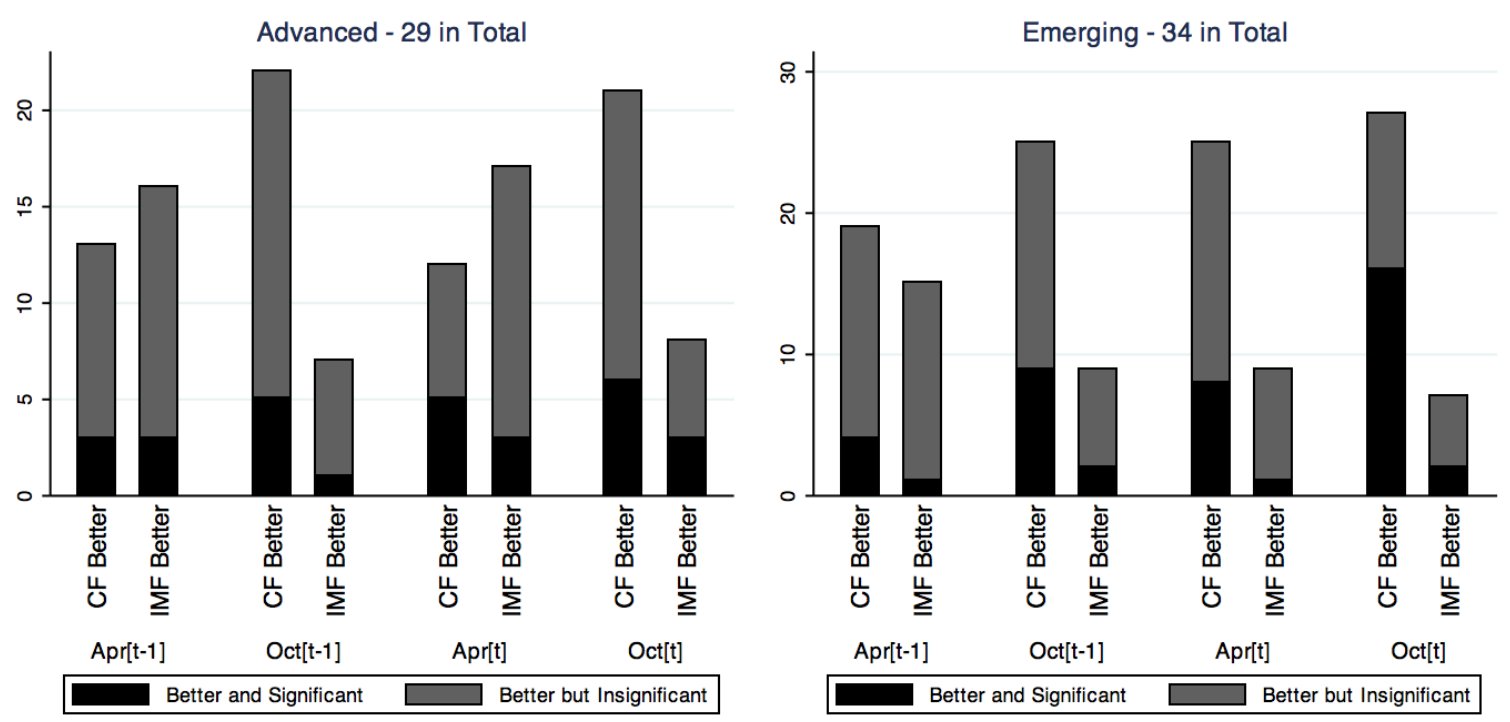

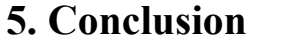

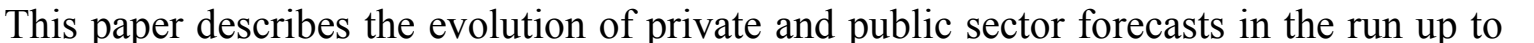

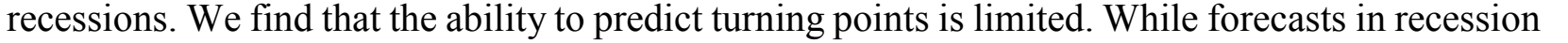

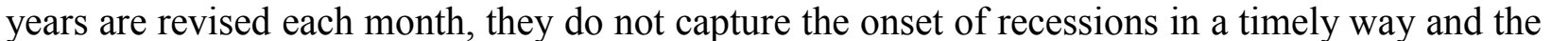

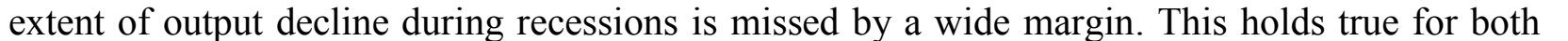

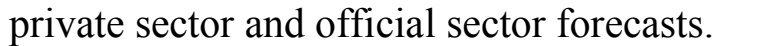

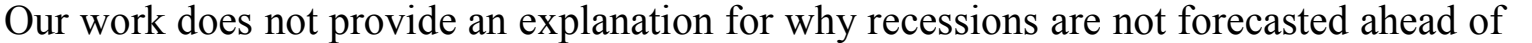

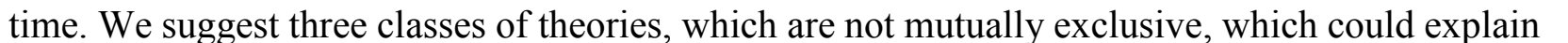

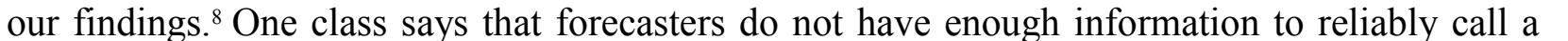

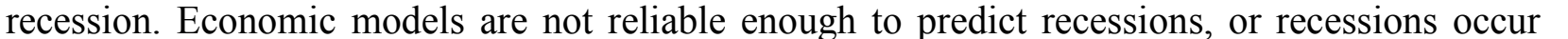

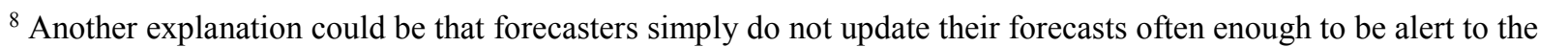

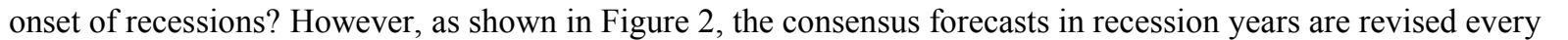

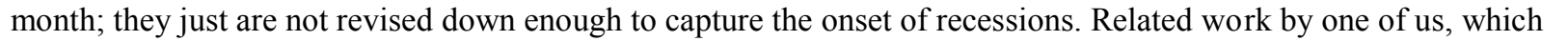

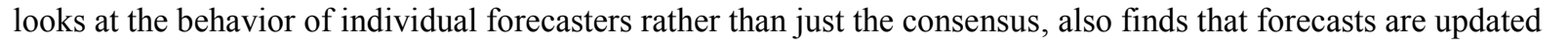

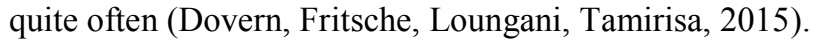




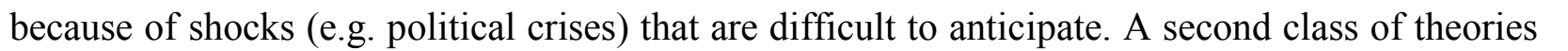

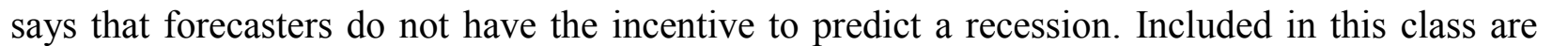

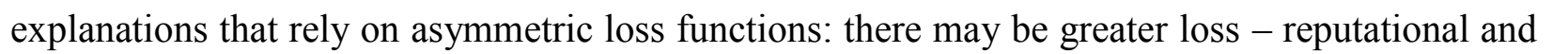

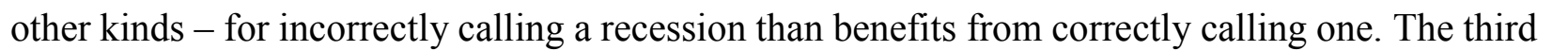

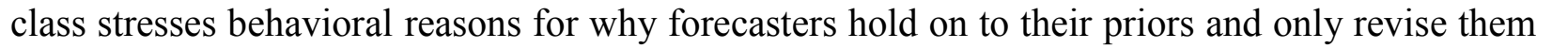

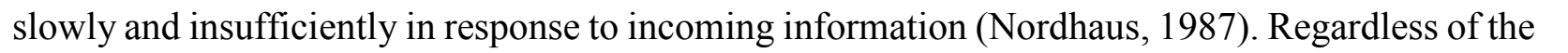

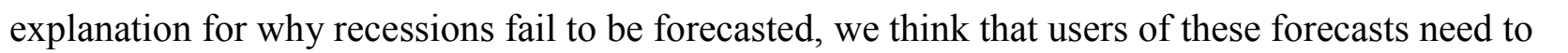

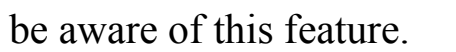

19

CInternational Monetary Fund. Not for Redistribution 


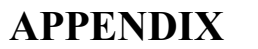

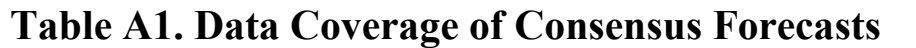

\begin{tabular}{|c|c|c|c|}
\hline$\square \square \square \| \square$ & 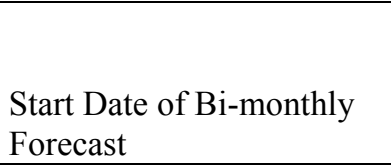 & 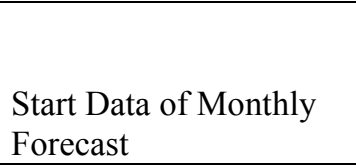 & 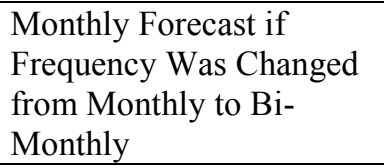 \\
\hline$\square$ & $\square$ & $\square \square\|\| \| ण म ा \square \square \square$ & $\square$ \\
\hline 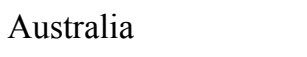 & $\square$ & $\square П \square \square$ & $\square$ \\
\hline 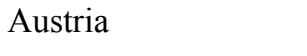 & $\square$ & एाएव & $\square$ \\
\hline पणाणम & $\square$ & $\square 1 \square \square$ & $\square$ \\
\hline$\square \square \square \square$ & $\square$ & $\square \square \square \square$ & $\square$ \\
\hline 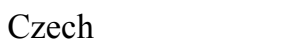 & एाए & एाए & $\square \prod \square$ \\
\hline पणपाण & $\square$ & ШШए & $\square$ \\
\hline पणाणम & $\square$ & $\square \prod \square \square$ & $\square$ \\
\hline पाणाए & $\square$ & $\square 1 \square \square$ & $\square$ \\
\hline पएणमा & $\square$ & $\square П \square \square$ & $\square$ \\
\hline पएणा & $\square$ & एामा & $\square$ \\
\hline 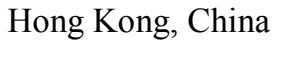 & $\square$ & $\square П \square$ & $\square$ \\
\hline घणाए & $\square$ & $\square П \square$ & $\square$ \\
\hline एणाய & $\square$ & $\square 1 \square \square$ & $\square$ \\
\hline घणाए & $\square$ & $\square П \square \square$ & $\square$ \\
\hline 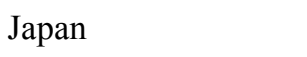 & $\square$ & $\square П \square \square$ & $\square$ \\
\hline पाणा & $\square \prod \square \square$ & $\square \square \square$ & $\square \prod \square \square$ \\
\hline 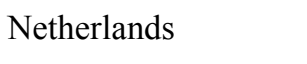 & $\square$ & ШШШ & $\square$ \\
\hline पमाणயம & $\square$ & एणम & $\square$ \\
\hline पणाए & $\square$ & $\square \square \square$ & $\square$ \\
\hline 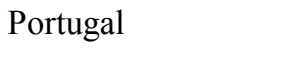 & $\square$ & $\square \square \square$ & $\square$ \\
\hline$\square[111 \square \square$ & एाए & एमा & $\square \square \square \square$ \\
\hline 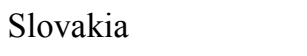 & $\square П \square$ & $\square П \square$ & $\square \square \square \square$ \\
\hline 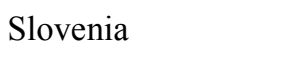 & $\square$ & $\square \prod \square$ & $\square$ \\
\hline 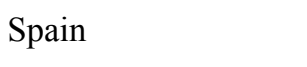 & $\square$ & $\square \prod \square \square$ & $\square$ \\
\hline प्माए & $\square$ & एाएम & $\square$ \\
\hline 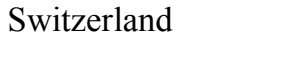 & $\square$ & $\square \square \square \square$ & $\square$ \\
\hline 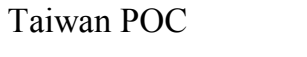 & $\square$ & $\square П \square$ & $\square$ \\
\hline 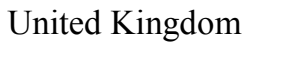 & $\square$ & $\square П \square$ & $\square$ \\
\hline 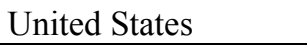 & $\square$ & $\square \square \square \square \square$ & $\square$ \\
\hline
\end{tabular}




\begin{tabular}{|c|c|c|c|}
\hline 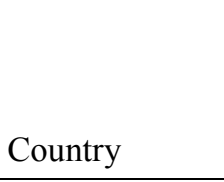 & 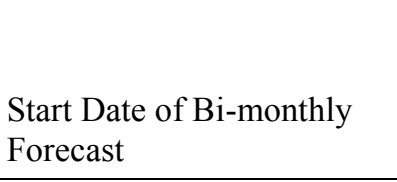 & 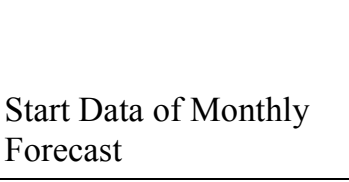 & 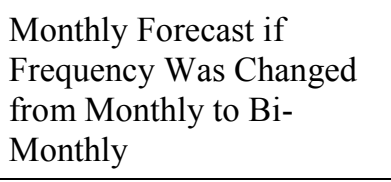 \\
\hline$\square$ & $\square$ & 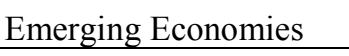 & $\square$ \\
\hline 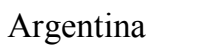 & $\square П \square \square$ & $\square П \square \square$ & $\square$ \\
\hline पएवाएण & $\square$ & $\square \square \square \square$ & $\square$ \\
\hline पणाणाण & $\square П \square \square$ & $\square \prod \square$ & $\square$ \\
\hline प्णापा & $\square \amalg \square$ & $\square \square \square \square$ & $\square \prod \square$ \\
\hline पमाणाए & $\square \square \square$ & $\square \square \square \square$ & $\square \square \square$ \\
\hline पणाणा & $\square \square \square \square$ & $\square \square \square \square$ & $\square$ \\
\hline$\square \square \square$ & $\square$ & $\square \square \square \square$ & $\square$ \\
\hline 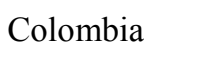 & एापए & $\square \prod \square \square$ & $\square$ \\
\hline 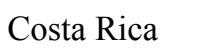 & $\square \square \square$ & $\square \square \square \square$ & $\square$ \\
\hline पमणाण & $\square \prod \square$ & $\square \prod \square \square$ & $\square$ \\
\hline$\square \square \amalg \square \mathbb{~}$ & $\square \amalg \square$ & $\square \amalg \square \square$ & $\square$ \\
\hline$\square \square 10$ & $\square$ & $\square \square \square \square$ & $\square$ \\
\hline 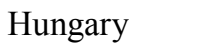 & $\square П \square \square$ & $\square \square \square \square$ & $\square П \square \square$ \\
\hline एापा & $\square$ & $\square \square \square \square$ & $\square$ \\
\hline 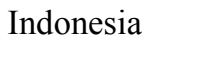 & $\square$ & एामए & $\square$ \\
\hline 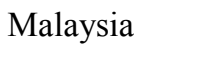 & $\square$ & $\square \square \square \square$ & $\square$ \\
\hline$\square \square \square \square$ & $\square П \square \square$ & $\square \square \square \square$ & $\square П \square \square$ \\
\hline पएवाणए & $\square$ & $\square \square \square$ & $\square$ \\
\hline पएमण & $\square \prod \square \square$ & $\square 1 \square \square$ & $\square$ \\
\hline पएणाएम & $\square \prod \square \square$ & एाए & $\square$ \\
\hline$\square \square \square$ & $\square \prod \square \square$ & $\square 1 \square \square$ & $\square$ \\
\hline पणतणमाणाए & $\square$ & एामण & $\square$ \\
\hline$\square \square \square \square$ & $\square \prod \square \square$ & $\square \square \square \square$ & $\square П \square$ \\
\hline$\square \square \square \square$ & $\square \prod \square \square$ & $\square \square \square \square$ & $\square \prod \square$ \\
\hline$\square \square \| ण \square$ & $\square$ & $\square \square \square \square$ & $\square$ \\
\hline 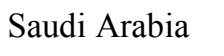 & $\square$ & $\square \square \square \square$ & $\square$ \\
\hline 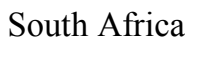 & $\square$ & पामपा & $\square$ \\
\hline 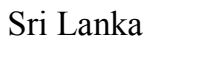 & $\square$ & एामपा & $\square$ \\
\hline पपाणाए & $\square$ & एामपा & $\square$ \\
\hline पपणाए & $\square \square \square$ & $\square \prod \square \square$ & एापए \\
\hline पमाயण & $\square П \square \square$ & $\square \square \square$ & $\square \square \square$ \\
\hline 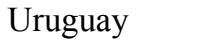 & $\square \square \square \square$ & $\square \sqcap \square \square$ & $\square$ \\
\hline पषाएाए & एामए & एामण & $\square$ \\
\hline पणापण口 & $\square$ & $\square \amalg \square \square$ & $\square$ \\
\hline
\end{tabular}

21

CInternational Monetary Fund. Not for Redistribution 


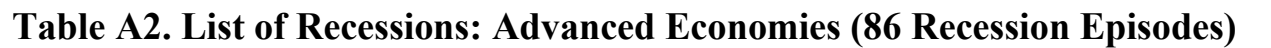

\begin{tabular}{|c|c|c|c|c|c|c|}
\hline 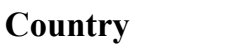 & \multicolumn{6}{|c|}{ 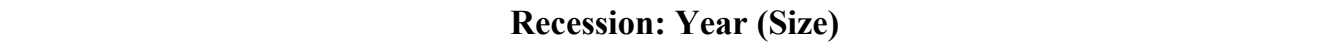 } \\
\hline 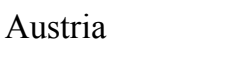 & 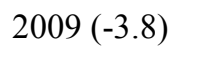 & $\square$ & $\square$ & $\square$ & $\square$ & $\square$ \\
\hline पणाणम & 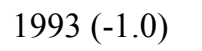 & 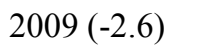 & $\square$ & $\square$ & $\square$ & $\square$ \\
\hline 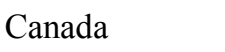 & 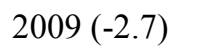 & $\square$ & $\square$ & $\square$ & $\square$ & $\square$ \\
\hline$\square \square\|\| \square$ & 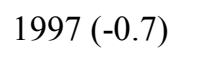 & 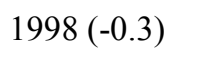 & 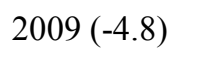 & 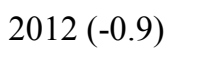 & 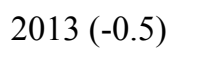 & $\square$ \\
\hline$\square \square \square \square \square \square$ & 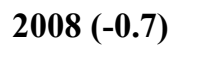 & 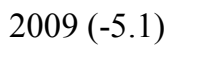 & 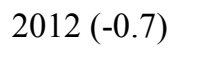 & 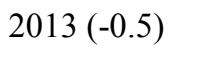 & $\square$ & $\square$ \\
\hline 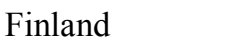 & 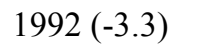 & $\square\|\| \| \square \square \square$ & 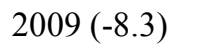 & 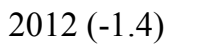 & $\square\|\Pi\| \square \square \square$ & 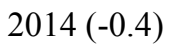 \\
\hline$\square \square \| \prod \square$ & 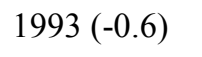 & 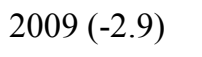 & $\square$ & $\square$ & $\square$ & $\square$ \\
\hline$\square \square \| \square \square \square$ & $\square|||||W| \square \mid \square$ & 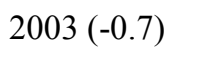 & 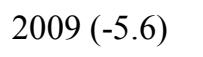 & $\square$ & $\square$ & $\square$ \\
\hline 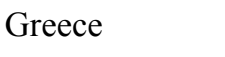 & 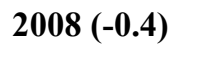 & 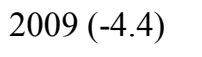 & 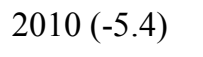 & 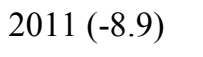 & 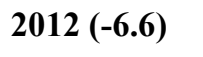 & 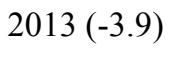 \\
\hline पएापाए & 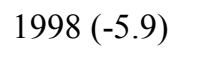 & 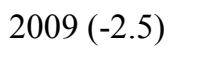 & $\square$ & $\square$ & $\square$ & $\square$ \\
\hline 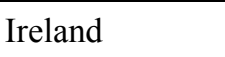 & 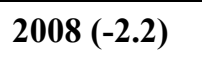 & 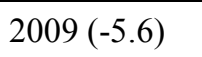 & $\square$ & $\square$ & $\square$ & $\square$ \\
\hline पा\|ा\|ा & 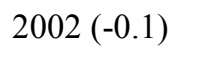 & $\square$ & $\square$ & $\square$ & $\square$ & $\square$ \\
\hline पाणाण & $\square \||\mathrm{m}| \mathrm{|l|}$ & 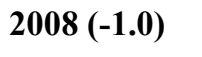 & $\square \||⿴ 囗 十| \square \square$ & 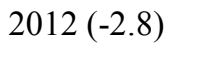 & 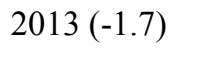 & 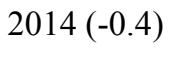 \\
\hline$\square \| \square \square$ & 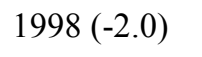 & 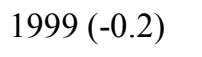 & 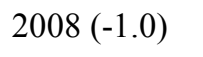 & 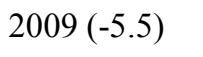 & 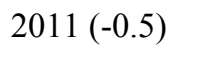 & 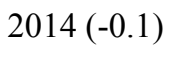 \\
\hline पणाए & 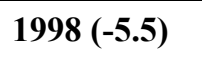 & $\square$ & $\square$ & $\square$ & $\square$ & $\square$ \\
\hline 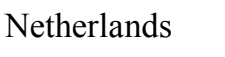 & 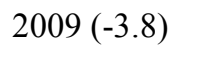 & 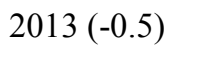 & 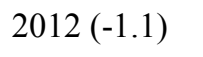 & $\square$ & $\square$ & $\square$ \\
\hline घमापामा & 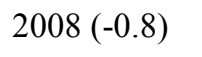 & $\square$ & $\square$ & $\square$ & $\square$ & $\square$ \\
\hline$\square \square \square \square \square$ & 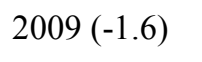 & $\square$ & $\square$ & $\square$ & $\square$ & $\square$ \\
\hline 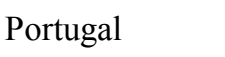 & 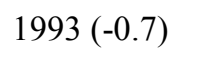 & 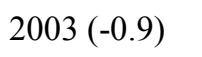 & 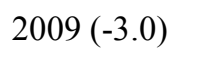 & 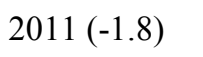 & 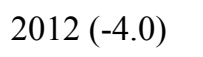 & 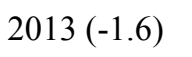 \\
\hline$\square[\|\|\|\| \square$ & 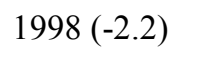 & 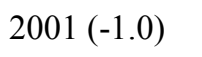 & 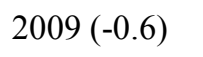 & $\square$ & $\square$ & $\square$ \\
\hline$\square \square\|ा\| \square$ & 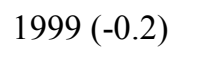 & $\square$ & 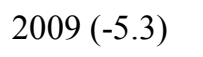 & $\square$ & $\square$ & $\square$ \\
\hline$\square \square \prod 1 \square \square$ & 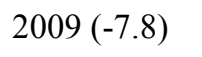 & 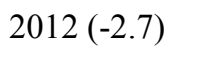 & 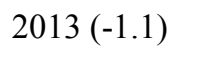 & $\square$ & $\square$ & $\square$ \\
\hline$\square \square \| \square$ & 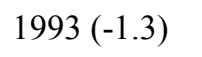 & 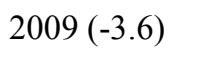 & 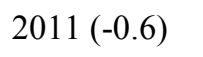 & 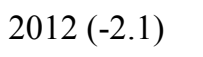 & 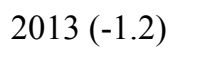 & $\square$ \\
\hline$\square \square \square \square \square$ & 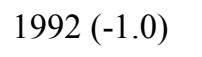 & 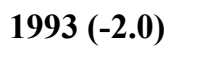 & 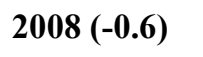 & 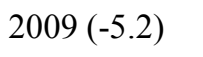 & 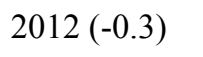 & $\square$ \\
\hline 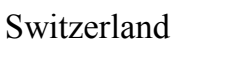 & 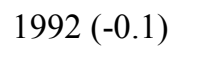 & 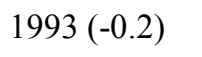 & 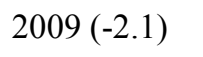 & $\square$ & $\square$ & $\square$ \\
\hline 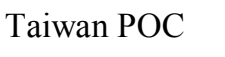 & 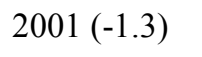 & 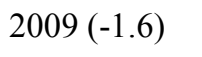 & $\square$ & $\square$ & $\square$ & $\square$ \\
\hline$\square \square \square$ & 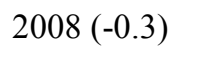 & 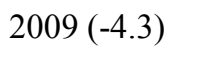 & $\square$ & $\square$ & $\square$ & $\square$ \\
\hline$\square \square \square \square$ & 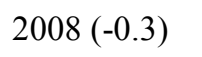 & 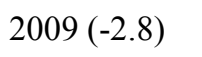 & $\square$ & $\square$ & $\square$ & $\square$ \\
\hline
\end{tabular}

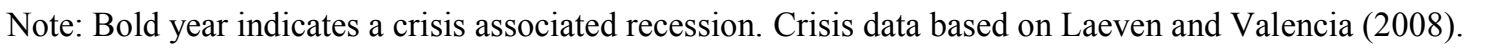




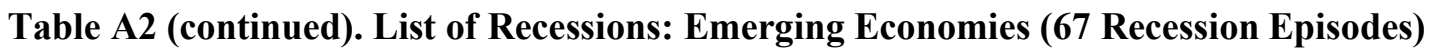

\begin{tabular}{|c|c|c|c|c|c|c|}
\hline 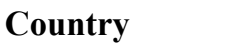 & \multicolumn{6}{|c|}{ 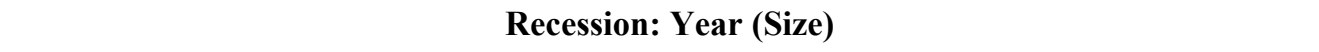 } \\
\hline 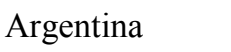 & 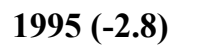 & 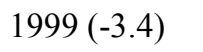 & पामाणाण & पामाणाप & $\square\|\|\|\| \| \square$ & $\square$ \\
\hline 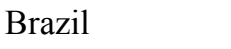 & 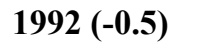 & 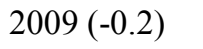 & $\square$ & $\square$ & $\square$ & $\square$ \\
\hline पवाणाण & 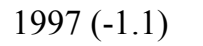 & 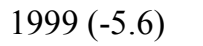 & 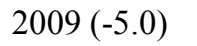 & $\square$ & $\square$ & $\square$ \\
\hline 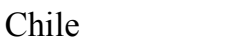 & 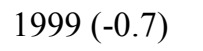 & 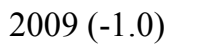 & $\square$ & $\square$ & $\square$ & $\square$ \\
\hline पणापणा & एाप⿴囗十丁口卄 & $\square$ & $\square$ & $\square$ & $\square$ & $\square$ \\
\hline पणயாणா & 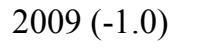 & $\square$ & $\square$ & $\square$ & $\square$ & $\square$ \\
\hline 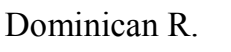 & 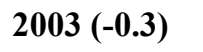 & $\square$ & $\square$ & $\square$ & $\square$ & $\square$ \\
\hline 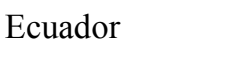 & 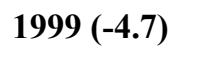 & $\square$ & $\square$ & $\square$ & $\square$ & $\square$ \\
\hline$\square \square \| \square \square$ & 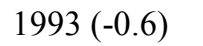 & 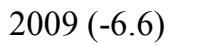 & 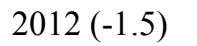 & $\square$ & $\square$ & $\square$ \\
\hline 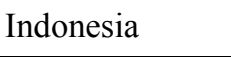 & 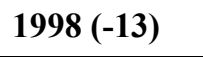 & $\square$ & $\square$ & $\square$ & $\square$ & $\square$ \\
\hline 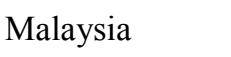 & 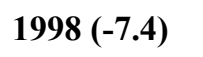 & 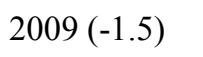 & $\square$ & $\square$ & $\square$ & $\square$ \\
\hline$\square \square \square \square \square$ & पापापण口卄 & 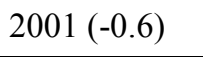 & पामापण口ण & $\square$ & $\square$ & $\square$ \\
\hline$\square \square\|\| \| \square$ & 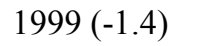 & 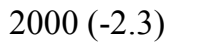 & 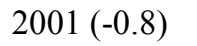 & 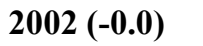 & 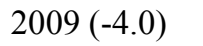 & 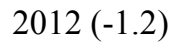 \\
\hline$\square \square \| \square$ & 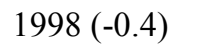 & $\square$ & $\square$ & $\square$ & $\square$ & $\square$ \\
\hline 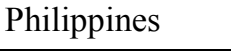 & 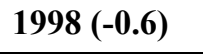 & $\square$ & $\square$ & $\square$ & $\square$ & $\square$ \\
\hline 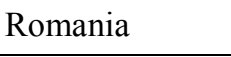 & 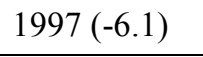 & 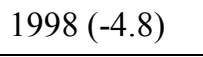 & 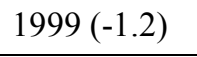 & 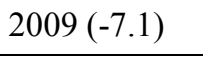 & 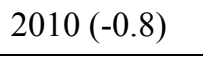 & $\square$ \\
\hline पाषणण & 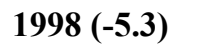 & 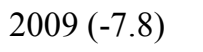 & $\square$ & $\square$ & $\square$ & $\square$ \\
\hline 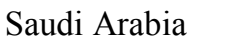 & 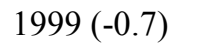 & $\square$ & $\square$ & $\square$ & $\square$ & $\square$ \\
\hline 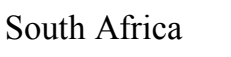 & 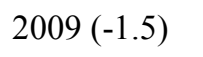 & $\square$ & $\square$ & $\square$ & $\square$ & $\square$ \\
\hline 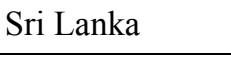 & 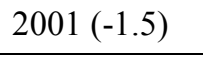 & $\square$ & $\square$ & $\square$ & $\square$ & $\square$ \\
\hline$\square \square\|\| \| \square$ & 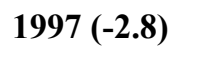 & 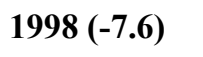 & 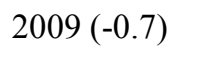 & $\square$ & $\square$ & $\square$ \\
\hline$\square \square \| \square \square$ & 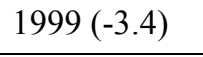 & 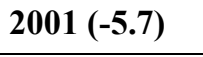 & 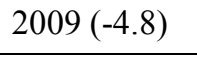 & $\square$ & $\square$ & $\square$ \\
\hline 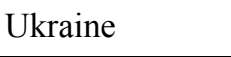 & 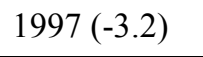 & 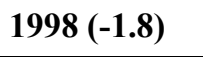 & 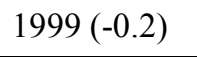 & 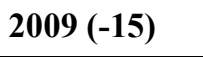 & 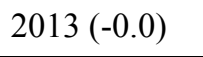 & 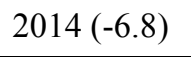 \\
\hline पषामा & 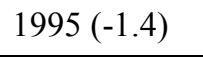 & 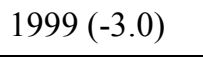 & पापापण口ण & 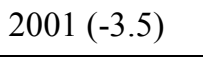 & 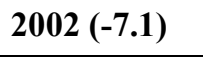 & $\square$ \\
\hline पालायाप & 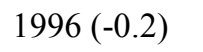 & पापाणमण & 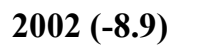 & 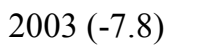 & 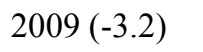 & पापा山ाणा \\
\hline$\square$ & 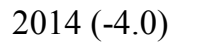 & $\square$ & $\square$ & $\square$ & $\square$ & $\square$ \\
\hline
\end{tabular}

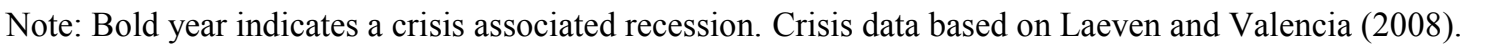

$\square$

$\square$

$\square$ 


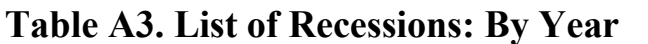

\begin{tabular}{|c|c|c|c|c|c|c|}
\hline$\square$ & $\square$ & $\square \square\|\| \| \Pi$ & $\square$ & $\square$ & प्वपणाण & $\square$ \\
\hline$\square 111$ & 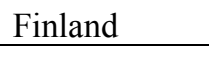 & $\square \square \square \prod \square$ & 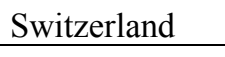 & 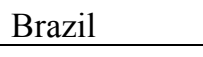 & $\square \square\|\|\|\| \square$ & $\square$ \\
\hline \multirow{3}{*}{ 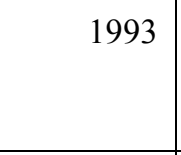 } & $\square \square ण \square \square \square$ & 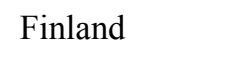 & $\square \square \square \square \square$ & $\square$ & $\square$ & $\square$ \\
\hline & $\square \square \square \square \square$ & पण口卄 & 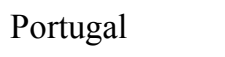 & $\square$ & $\square$ & $\square$ \\
\hline & \begin{tabular}{l|l|l|} 
\\
\end{tabular} & $\square \square \square \prod \square$ & 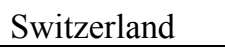 & $\square$ & $\square$ & $\square$ \\
\hline$\square \square 1$ & \multicolumn{2}{|c|}{$\square \square$} & $\square$ & $\square \square\|\|\|\|$ & $\square \square \square \square$ & $\square \square\|\| \prod$ \\
\hline$\square 111$ & \multicolumn{2}{|c|}{$\ulcorner\square$} & $\square$ & पपायाण & $\square$ & $\square$ \\
\hline \multirow{2}{*}{$\begin{array}{r}\square \longrightarrow \| \\
\quad \\
\end{array}$} & \multirow[t]{2}{*}{$\square \square \Pi \square$} & $\square$ & $\square$ & 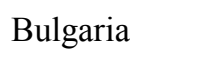 & पमएणा & $\square \square\|\| \| \square$ \\
\hline & & $\square$ & $\square$ & 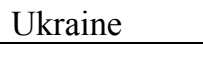 & $\square$ & $\square$ \\
\hline \multirow{3}{*}{$\square\|\|$} & \multirow{3}{*}{$\begin{array}{l}\square \square \prod \square \\
\square \square \| \square\end{array}$} & 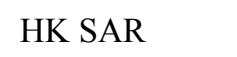 & $\square\|\| \square$ & 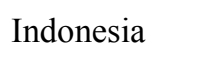 & $\square \square \square \mid\|\| \square$ & $\square \square \| \square$ \\
\hline & & $\square[|||||| \square$ & $\square$ & 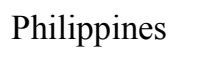 & $\square \square \square \square \square$ & $\square \square \mathbb{\| m}$ \\
\hline & & $\square$ & $\square$ & $\square \square\|\|\|\| \square$ & 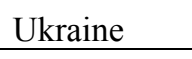 & $\square$ \\
\hline \multirow{4}{*}{ 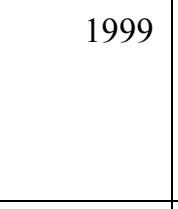 } & \multirow[t]{4}{*}{$\square\|\| \square$} & पएवामाप & $\square$ & 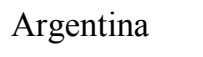 & 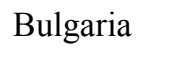 & पवाण \\
\hline & & $\square$ & $\square$ & 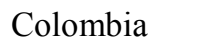 & $\square \square \square \mathbb{\|} \mid \mathbb{D}$ & $\square \square\|\|\|\| \square$ \\
\hline & & $\square$ & $\square$ & $\square \square \square \square \square$ & 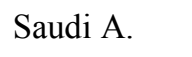 & $\square \square \| \square \square$ \\
\hline & & $\square$ & $\square$ & $\square \square\|\| \square$ & $\square \square\|\| \backslash$ & $\square \square\|\mathbb{\|}\| \mathbb{C}$ \\
\hline$\square \Pi 1$ & & $\square$ & $\square$ & 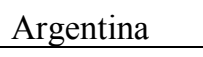 & $\square \square\|\|\|\| \square$ & 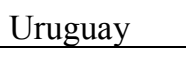 \\
\hline \multirow{2}{*}{$\square \| 1$} & \multirow[t]{2}{*}{ 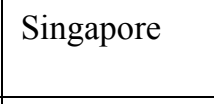 } & 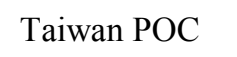 & $\square$ & 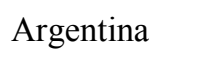 & $\square \square \square \square$ & $\square\|\|\|\| \square$ \\
\hline & & $\square$ & $\square$ & 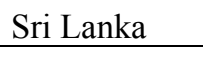 & $\square \square \square \square \square$ & $\square \square|\|| \square$ \\
\hline$\square 11$ & 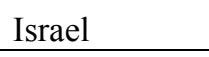 & $\square$ & $\square$ & $\square \square\|\| \| \square$ & $\square \square\|\|\|\|$ & $\square \square\|\| \square$ \\
\hline$\square 11$ & $\square \square \square \square \square$ & 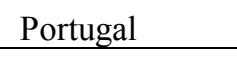 & $\square$ & पमापण & $\square \square\|\| \| M$ & $\square$ \\
\hline \multirow{3}{*}{$\begin{array}{r}\square 111 \\
\\
\\
4\end{array}$} & $\square \square \square \square \square \square$ & $\square \square \| \square \square$ & घாणाए & $\square$ & $\square$ & $\square$ \\
\hline & पण口冋 & $\|\square\| \square$ & पमापापा & $\square$ & $\square$ & $\square$ \\
\hline & 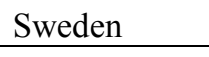 & $\square \square \square$ & $\square \square \square$ & $\square$ & $\square$ & $\square$ \\
\hline \multirow{9}{*}{ 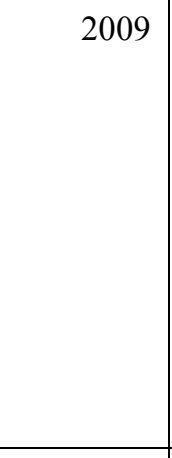 } & $\square \square\|m\|$ & $\square \square \mid ण 1 \square \square$ & $\square \square\|\| \square$ & $\square \square \square \| \square$ & 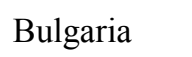 & $\square \square \| \square$ \\
\hline & $\square \square \amalg \square$ & $\square \square \square \square \square \square$ & 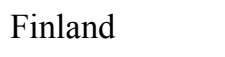 & पमापण口ण & $\square \square\|\| \| \square$ & $\square \square \square \mid \mathbb{D}$ \\
\hline & $\square \mathbb{\| \Perp \square ~}$ & $\square \square \mathbb{\square \square \square}$ & $\square \square\|\| \square$ & $\square \square \square \square$ & $\square \square\|\| \square \square \square$ & $\square \square \square \square \square$ \\
\hline & 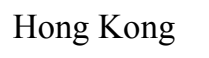 & एणाएण & एणाए & $\square \square \mathbb{1 0 \square}$ & पणमाण & $\square \square||\|\| \square$ \\
\hline & $\square \square \square \square$ & 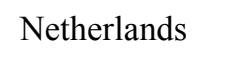 & $\square \square \square \square \square$ & $\square \square \| \square \square$ & पणा\|णम & 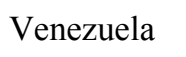 \\
\hline & 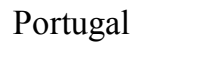 & पणमापण & पणमापा & $\square$ & $\square$ & $\square$ \\
\hline & $\square[11 \square \square$ & 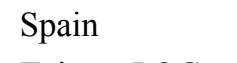 & $\square \square \square \square \square$ & $\square$ & $\square$ & $\square$ \\
\hline & 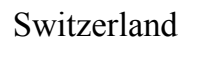 & 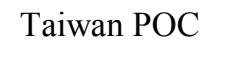 & $\square \square \square$ & $\square$ & $\square$ & $\square$ \\
\hline & $\square \square \square$ & $\square$ & $\square$ & $\square$ & $\square$ & $\square$ \\
\hline$\square 11$ & $\square \square\|\| \square$ & $\square$ & $\square$ & $\square \square \square \square \square$ & $\square \square\|\|\|\| \square$ & $\square$ \\
\hline \multirow[t]{2}{*}{$\square \square \square$} & $\square \square \| \Pi$ & 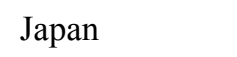 & 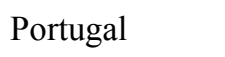 & $\square$ & $\square$ & $\square$ \\
\hline & \begin{tabular}{l|l|l|} 
\\
\end{tabular} & $\square$ & $\square$ & $\square$ & $\square$ & $\square$ \\
\hline \multirow{3}{*}{ 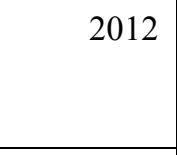 } & $\square \square \square \square \| \square$ & $\square[\|ा\| \square$ & $\square \square\|\| \square$ & $\square \square\|\| \| \square$ & $\square \square\|\|\|\| \square$ & $\square \square \square \square$ \\
\hline & 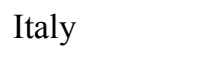 & 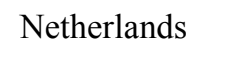 & 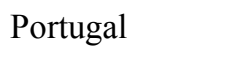 & $\square$ & $\square$ & $\square$ \\
\hline & 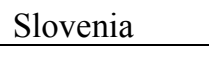 & 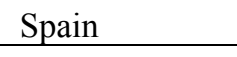 & 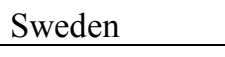 & $\square$ & $\square$ & $\square$ \\
\hline \multirow{3}{*}{ 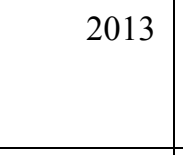 } & $\square \square \Pi \square$ & $\square \square \square \square \| \square$ & $\square[101 \square$ & $\square \square ण \square \square$ & $\square$ & $\square$ \\
\hline & 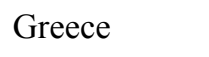 & पणाए & $\square \square|||||| \mid \mathbb{~}$ & $\square$ & $\square$ & $\square$ \\
\hline & 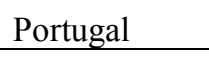 & \begin{tabular}{l|l|l|l|} 
\\
\end{tabular} & \begin{tabular}{l|l|l|} 
\\
\end{tabular} & $\square$ & $\square$ & $\square$ \\
\hline$\square \Pi 1$ & 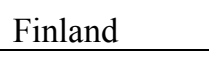 & पाणाण & \|\|$\| \square$ & $\square \square \| ा ण$ & $\square \square\|\|\|\|$ & $\square$ \\
\hline
\end{tabular}




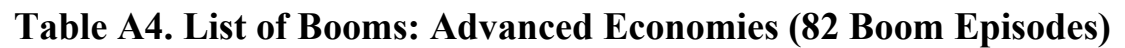

\begin{tabular}{|c|c|c|c|c|c|}
\hline \multirow{2}{*}{ 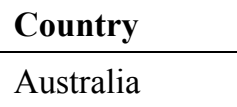 } & \multicolumn{5}{|c|}{$\square \square \square \square \square \square$} \\
\hline & $\square \square \square$ & $\square \square \square$ & $\square \square \square$ & $\square \square \square$ & $\square$ \\
\hline 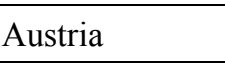 & $\square \square \square$ & $\square \square \square$ & $\square \square \square$ & $\square$ & $\square$ \\
\hline पणाणम & $\square \square \square$ & $\square \square \square$ & $\square \square \square$ & $\square \square \square$ & $\square$ \\
\hline$\square \square\|\| \square$ & $\square \square \square$ & $\square \square \square$ & $\square \square \square$ & $\square \square \square$ & $\square$ \\
\hline$\square \square \| \square$ & $\square \square \square$ & $\square \square \square$ & $\square \square \square$ & $\square$ & $\square$ \\
\hline$\square \square \square \square \square$ & $\square \square \square$ & $\square \square \square$ & $\square \square \square$ & $\square$ & $\square$ \\
\hline 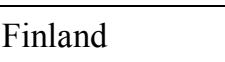 & $\square \square \square \square$ & $\square \square \square$ & $\square \square \square$ & $\square$ & $\square$ \\
\hline 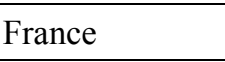 & $\square 11 \square$ & $\square \square \square$ & $\square \prod 1 \square$ & $\square$ & $\square$ \\
\hline$\square \square \square \square \square$ & $\square \square \square$ & $\square \square \square$ & $\square \prod \square$ & $\square \square \square$ & $\square$ \\
\hline 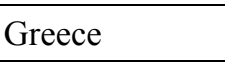 & $\square \square \square$ & $\square \square \square$ & $\square$ & $\square$ & $\square$ \\
\hline 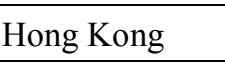 & $\square \square \square$ & $\square \square \square \square$ & $\square \square \square$ & $\square$ & $\square$ \\
\hline 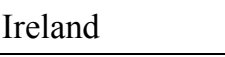 & $\square \prod \prod$ & $\square \prod \prod$ & $\square \prod \square$ & $\square \prod \square$ & $\square \prod \prod$ \\
\hline 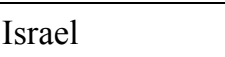 & $\square \square \square$ & $\square \square \square$ & $\square$ & $\square$ & $\square$ \\
\hline 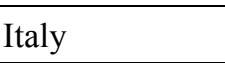 & $\square \square \square$ & $\square$ & $\square$ & $\square$ & $\square$ \\
\hline$\square\|1\|$ & $\square \square \square$ & $\square$ & $\square$ & $\square$ & $\square$ \\
\hline$\square \square \square \square$ & $\square \longrightarrow \square$ & $\square \longrightarrow \square$ & $\square \square \square$ & $\square \square \square$ & $\square$ \\
\hline 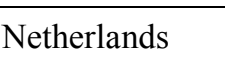 & $\square \square \square$ & $\square \square \square$ & $\square \square \square$ & $\square \square \square$ & $\square$ \\
\hline 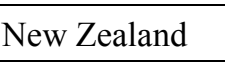 & $\square 11 \square$ & $\square \square \square$ & $\square$ & $\square$ & $\square$ \\
\hline$\square \square \| \square \square$ & $\square \square \square \square$ & $\square \square \square \square$ & $\square \square \square \square$ & $\square \square \square$ & $\begin{array}{l}\square \\
\end{array}$ \\
\hline 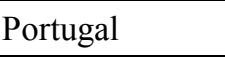 & $\square \square \square$ & $\square \square \square$ & $\square \square \square$ & $\square \square \square$ & $\square$ \\
\hline 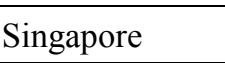 & $\square \square \square$ & $\square \square \square$ & $\square \square \square$ & $\square$ & $\square$ \\
\hline 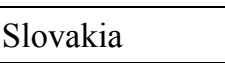 & $\square \square \square \square$ & $\square \square \square$ & $\square$ & $\square$ & $\square$ \\
\hline 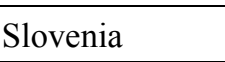 & $\square \square \square$ & $\square$ & $\square$ & $\square$ & $\square$ \\
\hline$\square \square \| \square$ & $\square \square \square \square$ & $\square \square \square \square$ & $\square$ & $\square$ & $\square$ \\
\hline 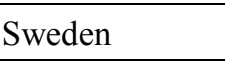 & $\square \square \square$ & $\square$ & $\square$ & $\square$ & $\square$ \\
\hline 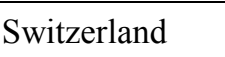 & $\square \longrightarrow \square$ & $\square \square \square$ & $\square \square \square$ & $\square$ & $\square$ \\
\hline 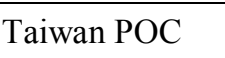 & $\square \square \square$ & $\square \square \square$ & $\square$ & $\square$ & $\square$ \\
\hline$\square \square \square$ & $\square \square \square \square$ & $\square \square \square$ & $\square$ & $\square$ & $\square$ \\
\hline$\square \square \square \square$ & $\square \square \square \square$ & $\square \square \square \square$ & $\square \square \square \square$ & $\square$ & $\square$ \\
\hline
\end{tabular}




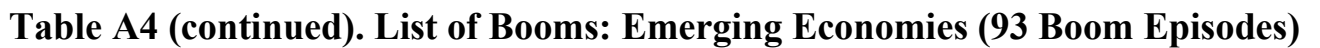

\begin{tabular}{|c|c|c|c|c|c|}
\hline \multirow{2}{*}{$\frac{\square \square \square\|\|}{\square \square \square\|\| \square}$} & \multicolumn{5}{|c|}{$\square \square \square \square \square \square$} \\
\hline & $\square \square \square$ & $\square \square \square$ & $\square \square \square$ & $\square$ & $\square$ \\
\hline$\square \square \square\|\| \square \square$ & $\square \square \square \square$ & $\square \square \square$ & $\square \square \square$ & $\square$ & $\square$ \\
\hline प०णाणा & $\square \square \square \square$ & $\square \square \square$ & $\square$ & $\square$ & $\square$ \\
\hline पषणाप & $\square \longrightarrow \square$ & $\square \longrightarrow \square$ & $\square \square \square$ & $\square \square \square$ & $\square$ \\
\hline पणाएणाए & $\square \longrightarrow \square$ & $\square \longrightarrow \square$ & $\square$ & $\square$ & $\square$ \\
\hline 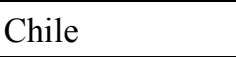 & $\square \square \square$ & $\square \square \square$ & $\square$ & $\square$ & $\square$ \\
\hline$\square \square \square \square$ & $\square \square \square$ & $\square \square \square$ & $\square \square \square$ & $\square$ & $\square$ \\
\hline पणापणाप & $\square \square \square$ & $\square \square \square$ & $\square \square \square$ & $\square$ & $\square$ \\
\hline 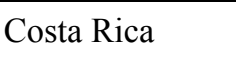 & $\square \square \square$ & $\square \square \square$ & $\square \square \square$ & $\square \square \square$ & $\square$ \\
\hline 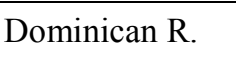 & $\square \square \square$ & $\square \square \square$ & $\square \square \square$ & $\square$ & $\square$ \\
\hline$\square \square\|\| \square$ & $\square \square \square \square$ & $\square \square \square$ & $\square \square \square$ & $\square$ & $\square$ \\
\hline$\square \square \square \square$ & $\square 11 \square$ & $\square \square \square$ & $\square П \square$ & $\square 11 \square$ & $\square$ \\
\hline$\square \square\|\| \square$ & $\square 11 \square$ & $\square$ & $\square$ & $\square$ & $\square$ \\
\hline पाणा & $\square 1 \square$ & $\square \prod 1 \square$ & $\square \prod \square$ & $\square \prod \square$ & $\square$ \\
\hline 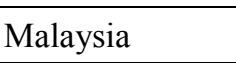 & $\square 1 \square$ & $\square \prod \square$ & $\square \prod \square$ & $\square$ & $\square$ \\
\hline$\square \square \square \square$ & $\square П \square$ & $\square \prod \square$ & $\square$ & $\square$ & $\square$ \\
\hline 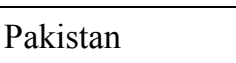 & $\square \square \square$ & $\square \square \square$ & $\square$ & $\square$ & $\square$ \\
\hline$\square \square \square \square$ & $\square \square \square$ & $\square \square \square$ & $\square \square \square$ & $\square \square \square \square$ & $\square$ \\
\hline$\square \square\|\|\|\| \square$ & $\square \square \square$ & $\square \square \square$ & $\square$ & $\square$ & $\square$ \\
\hline$\square \square \square$ & $\square \square \square$ & $\square \square \square$ & $\square \square \square$ & $\square$ & $\square$ \\
\hline$\square \square|\||||||||$ & $\square \square \square \square$ & $\square \square \square \square$ & $\square$ & $\square$ & $\square$ \\
\hline$\square \square\|\| \square$ & $\square \square \square$ & $\square \square \square$ & $\square \square \square$ & $\square \Pi \square$ & $\square \Pi \square$ \\
\hline 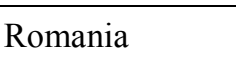 & $\square \prod \square$ & $\square \prod \square$ & $\square \prod \square$ & $\square$ & $\square$ \\
\hline$\square \square\|\| \square$ & $\square \square \square \square$ & $\square$ & $\square$ & $\square$ & $\square$ \\
\hline 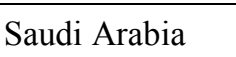 & $\square \square \square$ & $\square \square \square$ & $\square \square \square$ & $\square \square \square$ & $\square$ \\
\hline 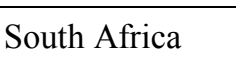 & $\square \square \square \square$ & $\square \square \square$ & $\square \square \square$ & $\square$ & $\square$ \\
\hline 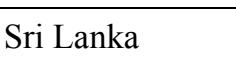 & $\square \square \square \square$ & $\square$ & $\square$ & $\square$ & $\square$ \\
\hline$\square \square\|\| \square \square$ & $\square \square \square$ & $\square \square \square$ & $\square \square \square$ & $\square$ & $\square$ \\
\hline$\square \square \| 11 \square$ & $\square \square \square \square$ & $\square \square \square$ & $\square \square \square$ & $\square$ & $\square$ \\
\hline 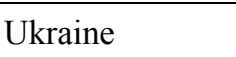 & $\square \square \square$ & $\square \square \square$ & $\square \square \square$ & $\square$ & $\square$ \\
\hline$\square \square म 11 \square$ & $\square \square \square$ & $\square \prod 1 \square$ & $\square$ & $\square$ & $\square$ \\
\hline$\square \square\|\| \| \square$ & $\square \square \square$ & $\square \square \square$ & $\square \square \square$ & $\square$ & $\square$ \\
\hline 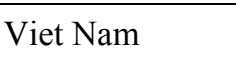 & $\square \square \square$ & $\square \square \square$ & $\square \square \square$ & $\square$ & $\square$ \\
\hline
\end{tabular}




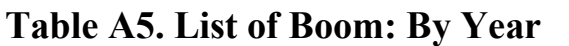

\begin{tabular}{|c|c|c|c|c|c|c|c|}
\hline$\square$ & $\square$ & $\square \square\|\| \|$ & $\square$ & \multicolumn{4}{|c|}{ 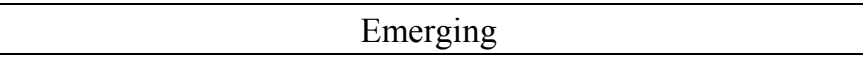 } \\
\hline$\square 11$ & \begin{tabular}{|l|l|l|l|} 
\\
\end{tabular} & $\square$ & $\square$ & $\square$ & $\square$ & $\square$ & $\square$ \\
\hline$\square 11$ & $\square[11110$ & $\square$ & $\square$ & 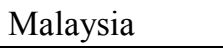 & $\square \square\|\| ण \square$ & $\square$ & $\square$ \\
\hline$\square \square \square$ & 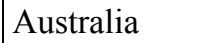 & $\square \square \square \square$ & $\square \square \square \square \square$ & पणाणाण & $\square \square\|\| \sqcap \square$ & $\square$ & $\square$ \\
\hline$\square$ & $\square \square ण \square$ & $\square \square \square \square \| ा ए$ & $\square \square \square \square \square$ & $\square$ & $\square$ & $\square$ & $\square$ \\
\hline$\square$ & $\square[111110$ & $\square \square \square$ & $\square$ & $\square$ & $\square$ & $\square$ & $\square$ \\
\hline$\square 111$ & 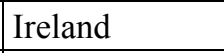 & 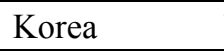 & 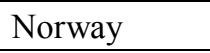 & \begin{tabular}{|l|l|}
$\square \square म$ \\
\end{tabular} & 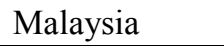 & 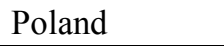 & पपाणाए। \\
\hline$\square 11$ & 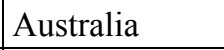 & पण口冋ए। & $\square \square \square \square \square$ & 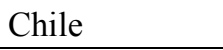 & 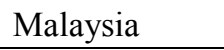 & $\square \square \square \square$ & $\square \square \square \square \square$ \\
\hline$\square 11$ & 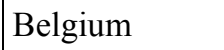 & $\square \square \square \square \square$ & $\square \| \square \square \square$ & $\square \square \square \square$ & $\square \square \square \square \square$ & 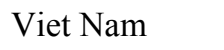 & $\square$ \\
\hline$\square$ & एणमा & 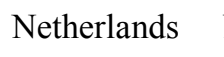 & $\square \square \square \square$ & $\square$ & $\square$ & $\square$ & $\square$ \\
\hline$\square$ & 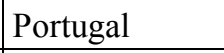 & $\square \square \square \square$ & $\square$ & $\square$ & $\square$ & $\square$ & $\square$ \\
\hline$\square \longrightarrow \square$ & 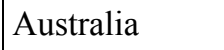 & 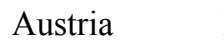 & 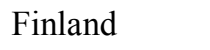 & पणमाणमाण & $\square \square \square \square$ & $\square$ & $\square$ \\
\hline$\square$ & 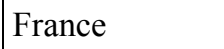 & 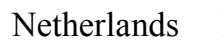 & $\square \square \| \square \square \square$ & $\square$ & $\square$ & $\square$ & $\square$ \\
\hline$\square$ & $\square \square \square \square$ & $\square$ & $\square$ & $\square$ & $\square$ & $\square$ & $\square$ \\
\hline$\square 1 \square$ & 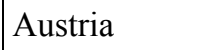 & 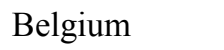 & $\square \square \square \square \square$ & पपणाणमाण & $\square$ & $\square$ & $\square$ \\
\hline$\square$ & $\square \square \| 1 \square$ & एण口冋 & पवणा & $\square$ & $\square$ & $\square$ & $\square$ \\
\hline$\square$ & 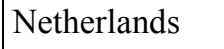 & $\square \square \square \square \square \square$ & $\square \square \square$ & $\square$ & $\square$ & $\square$ & $\square$ \\
\hline$\square$ & $\square \square \square \square$ & $\square$ & $\square$ & $\square$ & $\square$ & $\square$ & $\square$ \\
\hline$\square \square \square$ & पढणाएव & $\square \square \square \square$ & $\square \square \square \square \square$ & 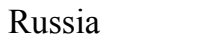 & $\square$ & $\square$ & $\square$ \\
\hline$\square$ & $\square \mathrm{mW}$ & 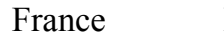 & 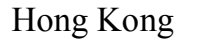 & $\square$ & $\square$ & $\square$ & $\square$ \\
\hline$\square$ & एणाणा & घणमाण & एणाए & $\square$ & $\square$ & $\square$ & $\square$ \\
\hline$\square$ & $\square \square ण \square$ & 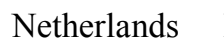 & $\square \square \| \square \square \square$ & $\square$ & $\square$ & $\square$ & $\square$ \\
\hline$\square$ & 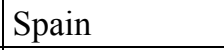 & 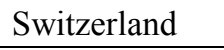 & $\square$ & $\square$ & $\square$ & $\square$ & $\square$ \\
\hline$\square \square \square$ & $\square$ & $\square$ & $\square$ & पपणा। & $\square$ & $\square$ & $\square$ \\
\hline$\square \square \square$ & 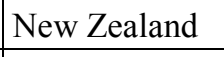 & $\square$ & $\square$ & $\square$ & $\square$ & $\square$ & $\square$ \\
\hline$\square \longrightarrow \square$ & $\square \square \| 1 \square$ & $\square \square \square$ & $\square$ & 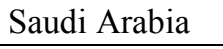 & $\square \square\|\| \| \square$ & $\square$ & $\square$ \\
\hline$\square \longrightarrow \square$ & पणणाणम & 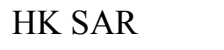 & $\square$ & पषणाणाए & 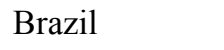 & 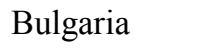 & $\square \square\|\| \| \mathbb{D}$ \\
\hline$\square$ & $\square$ & $\square$ & $\square$ & $\square \square\|1\| \square$ & $\square \square\|\| \| \square \square$ & पमणाण & 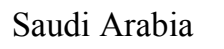 \\
\hline$\square$ & $\square$ & $\square$ & $\square$ & $\square \square \square \square \square$ & $\square \square\|\| ण \square$ & 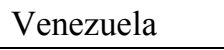 & $\begin{array}{l}\square \| ण म \square \\
\end{array}$ \\
\hline$\square 11$ & $\square \square \square \square$ & 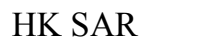 & $\square$ & 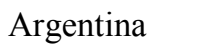 & $\square \square ण \square$ & 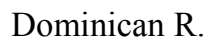 & 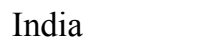 \\
\hline$\square$ & $\square$ & $\square$ & $\square$ & 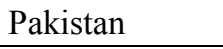 & 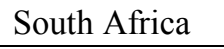 & पपाएाए & 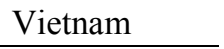 \\
\hline$\square 1 \square$ & $\square \square \square \square$ & $\square \square \square \square \square$ & $\square \square \square \square \square$ & पमापापण & $\square \square ण \square$ & पणणमणप & पवणाणमाण \\
\hline$\square$ & $\square \square \| 1 \square$ & 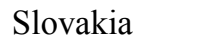 & 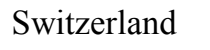 & 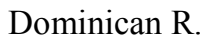 & $\square \square \square \|$ & घाणा & $\square \square \square \square \square$ \\
\hline$\square$ & $\square$ & $\square$ & $\square$ & 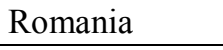 & 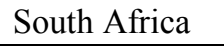 & पणाणाण & $\square \square|||||| \mid \square$ \\
\hline$\square \longrightarrow \square$ & 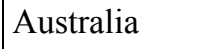 & 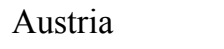 & पएाए & प्णाणा & 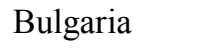 & पवणा & 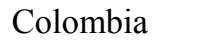 \\
\hline$\square$ & $\square \square \square \square \square$ & घण口冋 & 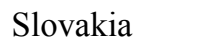 & पपणाणमाण & घாயாயா & $\square \square \square \mathbb{W}$ & एाण \\
\hline$\square$ & 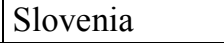 & 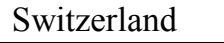 & $\square$ & $\square \square \square \square$ & $\square \square \| \square$ & $\square \square \square \square \square$ & 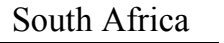 \\
\hline$\square \square \square$ & $\square$ & $\square$ & $\square$ & पमणाण & $\square \square \square \square \square \mathbb{~}$ & $\square \square \square \|$ & $\square \square \square \square$ \\
\hline$\square$ & $\square$ & $\square$ & $\square$ & $\square \square \square \square$ & 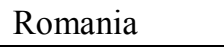 & 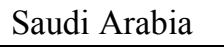 & $\square \square ा 111$ \\
\hline$\square \square \square$ & $\square \square \square \square \square$ & $\square \square \square$ & 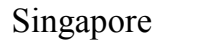 & 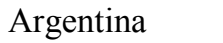 & पण口冋 & एण口 & $\square \square \| \square \square \square$ \\
\hline$\square$ & $\square \square \square \| \square$ & 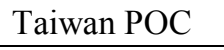 & $\square$ & $\square \square \square \square$ & 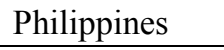 & $\square \square \square \square \square$ & $\square \square \| 111$ \\
\hline$\square \longrightarrow \square$ & $\square \square \square \square \square$ & $\square$ & $\square$ & पणाणमाए & 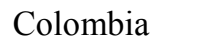 & $\square \square \square\|ा\|$ & $\square \square \square \square \square$ \\
\hline$\square$ & $\square$ & $\square$ & $\square$ & 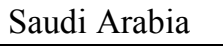 & 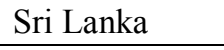 & $\square \square \square \square \square$ & $\square$ \\
\hline$\square \square \square$ & $\square$ & $\square$ & $\square$ & $\square \square \square \square$ & $\square$ & $\square$ & $\square$ \\
\hline$\square \square \square$ & $\square$ & $\square$ & $\square$ & 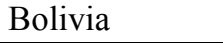 & $\square \square \| \square \square \square$ & 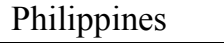 & $\square$ \\
\hline
\end{tabular}

27

CInternational Monetary Fund. Not for Redistribution 


\section{Panel A. Consensus Forecasts}
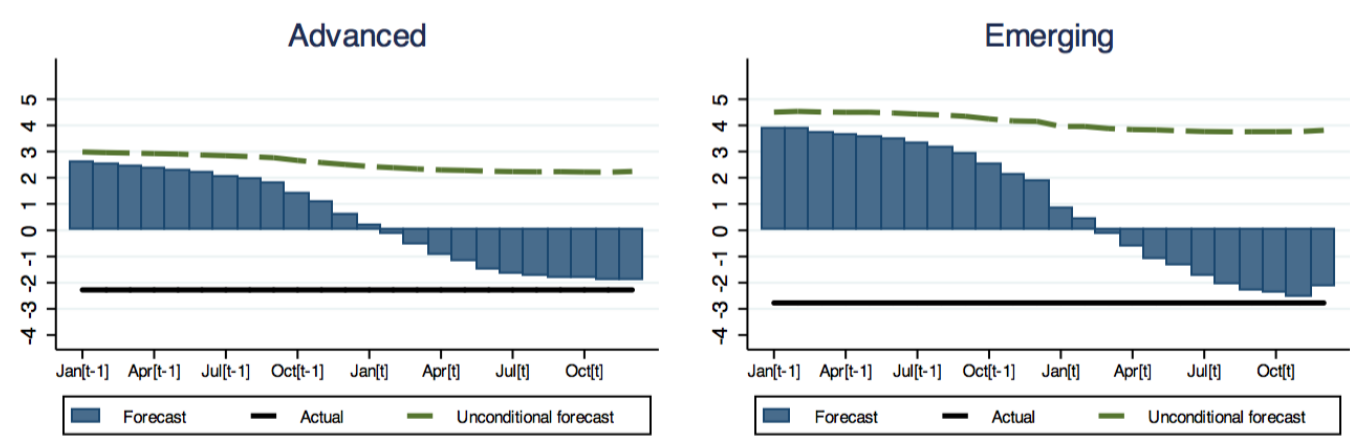

Panel B. IMF Forecasts
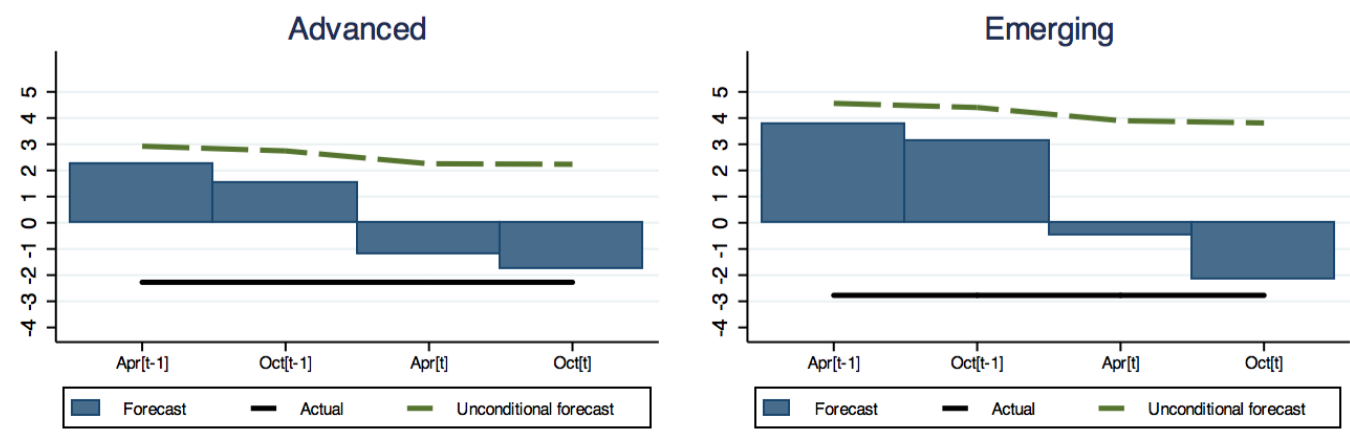


\section{पाणापापाण}

1. Abreu, I. (2011), "International Organisations' vs. Private Analysts' Forecasts: An Evaluation”, Banco de Portugal Working Paper, 21/2011.

$\square \mathrm{mll}$ Batchelor, R. and P. Dua (1995), "Forecaster Diversity and the Benefits of Combining

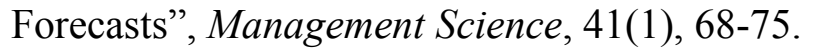

Coibion, O. and Y. Gorodnichenko (2015), "Information Rigidity and the Expectations $\square \square\|\square \square \square\|$ rocess: A Simple Framework and New Facts", American Economic Review $\square \square \|$

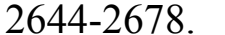

$\square \mathrm{WU}$ Coibion, O. and Y. Gorodnichenko (2012), "What can survey forecasts tell us about

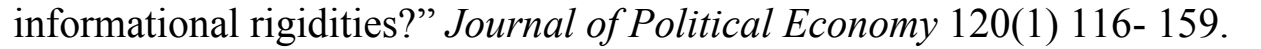

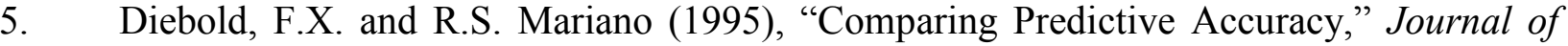
Business and Economic Statistics $\square \square \square \square-\square \square \square$

Dovern, J. (2013), "When Are GDP Forecasts Updated? Evidence from a Large

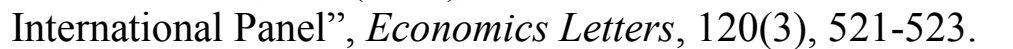

$\square \Pi m \square \square \square \square \| \Pi$, U. Fritsche, and J. Slacalek (2012), “Disagreement among Forecasters in G7 Countries", Review of Economics and Statistics $\square||||||||||||||||$

Dovern, J., U. Fritsche, P. Loungani, and N. Tamirisa (2015), "Information Rigidities:

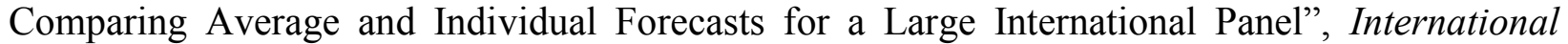

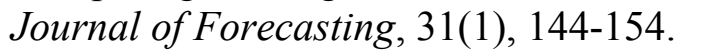

Dovern, J. and N. Jannsen (2017), "Systematic Errors in Growth Expectations over the

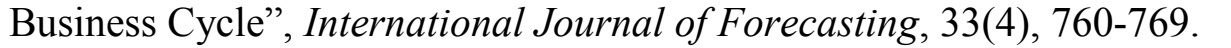

Fintzen, D. and H.O. Stekler (1999), "Why Did Forecasters Fail to Predict the 1990

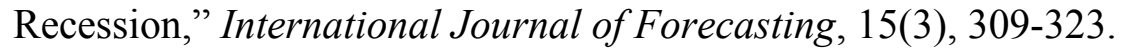

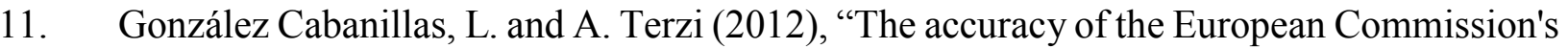

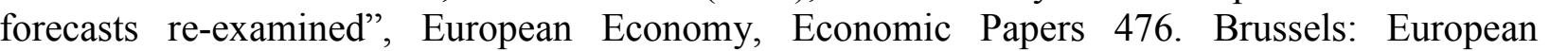

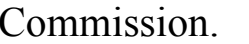

IMF, Independent Evaluation Office (2014), “IMF Forecasts: Process, Quality and Country Perspectives".

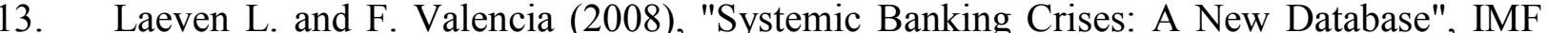

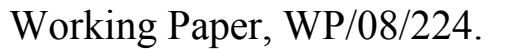

$\square \mathrm{Wm}$ Lewis, C. and N. Pain (2015), "Lessons from OECD Forecasts during and after the Financial Crisis", OECD Journal: Economic Studies $\square|||||||||||| \overrightarrow{\mid}$

oungani, P. (2001), "How Accurate are Private Sector Forecasts? Cross $\square \| \square|\square| \square \square \square \square \square \square \square$ from Consensus Forecasts of Output Growth", International Journal of Forecasting $\square \square|\|\backslash\| \square|$

$\square \square \square$ Loungani, P., H. Stekler, and N. Tamirisa (2013), "Information Rigidity $\square \square \square \square \square \square \square$

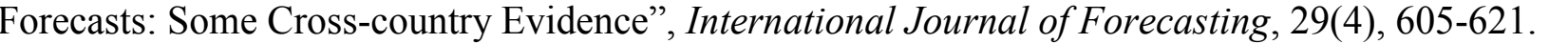

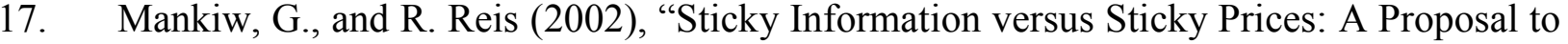

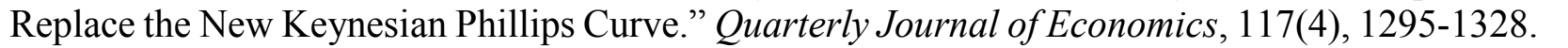


$\square \mathrm{m} \|$ Nordhaus, W. (1987), "Forecasting Efficiency: Concepts and Applications", Review of

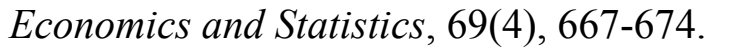

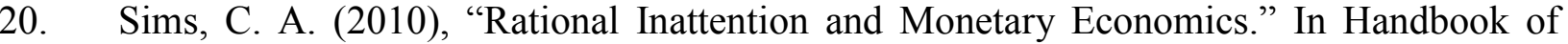

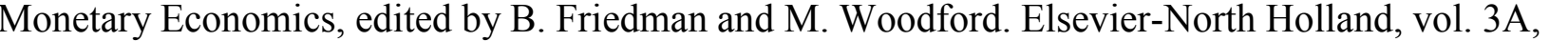

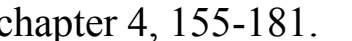

$\square \square \mathrm{W}$ Sinclair, T. M., F. Joutz, and H. Stekler (2010), "Can the Fed Predict the State of the Economy?", Economics Letters

$\square \square \mathrm{W}$ Woodford, M. (2003), “Interest and Prices: Foundations of a Theory of Monetary Policy”,

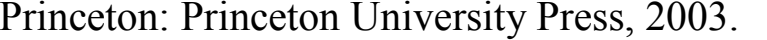

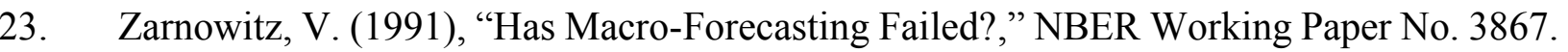

